Article

\title{
Incorporation of Torsional \& Higher-Mode Responses in Displacement-Based Seismic Design of Asymmetric RC Frame Buildings
}

\author{
Beka Hailu Abebe and Jong Seh Lee * \\ Department of Civil and Environmental Engineering, Hanyang University, Ansan 15588, Korea; \\ beka2013@hanyang.ac.kr \\ * Correspondence: jonglee@hanyang.ac.kr; Tel.: +82-31-400-5146
}

Received: 19 December 2018; Accepted: 11 March 2019; Published: 15 March 2019

check for updates

Featured Application: This article proposes a displacement-based seismic design procedure for asymmetric RC frame buildings.

\begin{abstract}
Direct Displacement-Based Design (DDBD) is currently a widely used displacement-based seismic design method. DDBD accounts for the torsional response of Reinforced Concrete (RC) frame buildings by using semi-empirical equations formulated for wall-type buildings. Higher-mode responses are incorporated by using equations obtained from only a few parametric studies of regular planar frames. In this paper, there is an attempt to eliminate torsional responses by proportioning frames' secant stiffnesses so that the centers of rigidity and supported mass (the mass on and above each story) coincide. Once the torsional rotations are significantly reduced and only translational motions are achieved, higher-mode responses are included using a technique developed by the authors in their recent paper. The efficiency of the proposed design procedure in fulfilling the intended performance objective is checked by two plan-asymmetric 20-story RC frame building cases. Case-I has the same-plan configuration while Case-II has a different-plan configuration along the height. Both cases have different bay widths in orthogonal directions. Verification of the case studies by Nonlinear Time History Analysis (NTHA) has shown that the proposed method results in designs that satisfy the performance objective with reasonable accuracy without redesigning members. It is believed that a step forward is undertaken toward rendering design verification by NTHA less necessary, thereby saving computational resources and effort.
\end{abstract}

Keywords: effective modal superposition; direct displacement-based design; performance-based seismic design; plan-asymmetric RC frame buildings; torsion effects; higher-mode effects

\section{Introduction}

A reliable Performance-Based Seismic Design (PBSD) uses a probabilistic design approach to achieve performance objectives (Bertero and Bertero [1], Collins and Stojadinovic [2], and Castaldo et al. [3]). However, PBSD is implemented for routine design using simplified design methods like the displacement-based design and force-based design. This is due to the complex nature of the probabilistic design approach and scarcity of data on experiments, fragility curves, cost functions, damage states, and so on. Currently, the displacement-based design is found to be a better choice than force-based design since problems with force-based design have been clearly identified by Priestley [4], and damage is correlated with displacements (strains) than forces (stresses). Various displacement-based design methods have been developed, which can be categorized into two types (Bertero and Bertero [1]). The first type, discussed in Mohele [5] and Applied Technology Council 
(ATC)-40 [6], uses force-based design and checks whether allowable displacements are exceeded. The second type uses allowable displacements at the start of the design process (Priestley [4], Aschheim and Black [7], and Chopra and Goel [8]). While the above displacement-based methods are proposed for general design purposes, many more were devised for a specific type of lateral-load resisting system concentrating on higher-mode and/or torsional effects and are discussed briefly below.

Castillo [9] proposed a seismic design procedure, which is applicable for buildings that can be analyzed using the equivalent static method. The procedure must be extended for multi-story systems with setbacks and regular asymmetry as defined by Hejal and Chopra [10]. The effect of higher modes on the seismic demand is also not addressed. Fazileh [11] devised a displacement-based seismic design procedure for RC planar wall-frame buildings and plan-asymmetric wall buildings. The design is improved by multimode pushover analysis so that seismic demands from first- and higher-modes are not exceeded. In the study, NTHA outputs show that displacements are overestimated while story shears are reasonably accurate.

There are various efficient methods of seismic design verification that consider explicitly the nonlinear torsional and higher-mode effects by Colajanni [12], Ferraioli [13], Ferraioli et al. [14], Kaatsiz and Sucuoğlu [15], Kreslin and Fajfar [16], and Landi et al. [17] to cite a few. Further literature on seismic design verification procedures is discussed in detail by De Stefano, M. and Pintucchi, B. [18]. Based on one of the available procedures (i.e., using the modal pushover analysis principle by Chopra and Goel [19]), Wilkinson and Lavan [20] developed design methods termed as modal pushover design and direct modal pushover design. The methodologies were tested for one-way asymmetric wall buildings for which modal coupling due to yielding is insignificant. Both methods, in addition to being computationally intensive, produce a conservative estimate of drifts in some walls because the design process is governed by a given story's allowable drift or wall curvature. The aforementioned shortcomings were minimized by the authors in their proposed design method called practical modal pushover design [21]. It is based on an inverse process of practical modal pushover analysis by Reyes and Chopra [22]. Other steps are the same as the modal pushover design and direct modal pushover design. Though computationally less intensive, its performance is less than a modal pushover design. The authors recommended that the shear actions obtained using the method be amplified by the flexural reinforcing steel over-strength factor. Furthermore, the frame-section's shear capacities incorporate the material strength reduction factors.

Georgoussis [23] presented a preliminary seismic design method for low and medium height $\mathrm{RC}$ wall-frame buildings accounting for the torsional response. The procedure calculates the distance of a given arbitrary wall which coincides with the center of mass and the modal center of rigidity. NTHA of the case study shows that the lowest roof rotation is indeed achieved when the center of mass and rigidity are aligned on an axis. However, NTHA produces a base shear demand that exceeds the strength due to the higher-mode responses. The paper does not address the effect of the center of mass variation along the height or strength assignment for fixed positions of the walls and frames.

Bahmani et al. [24] developed a displacement-based procedure for plan asymmetric multi-story buildings. It decouples the translational and torsional deformations using an approximate technique formulated by Kan and Chopra [25]. The method is found to be accurate for linear systems. On the other hand, NTHA of a nonlinear (elastic-perfectly plastic) system showed that it is conservative in achieving the allowable story drift; hence, it needed further refinement. The P- $\Delta$ effect is checked after the design is completed. If the stability coefficient is greater than 0.1 , redesign is necessary.

To incorporate torsional responses in DDBD's framework, Beyer [26] derived semi-empirical equations for estimating twist-induced displacements of plan-asymmetric wall buildings. These equations are limited for use in the seismic design of torsionally restrained regular-asymmetric systems. Paparo et al. [27] applied the semi-empirical equations to two asymmetric RC frame buildings having the same geometry but different lateral strength distribution along the plan. The case studies did not account for the effects of P- $\Delta$ and center of mass variation along the height. The mean NTHA story displacements are low compared to the design displacements for both cases. The NTHA confirmed 
that design for different strength assignment (zero strength eccentricity) resulted in lower floor rotation than design for equal strength. The mean NTHA drifts have exceeded the allowable first-story drifts for some frames even though the difference is only about 5 percent. The plastic hinge rotations of the members were also not discussed.

Many researchers have attempted to incorporate higher-mode effects in DDBD's framework. Loeding et al. [28] formulated parametric equations of story displacements for application in DDBD of RC frames. Pettinga and Priestley [29] modified the equations to include drift amplification due to higher modes. The case studies range from two to 20-story vertically regular tube frames, thus not representative of typical frames with longer beam spans where gravity load action may dominate. The P- $\Delta$ effect is also not considered. Suarez [30] discussed that the P- $\Delta$, building height, number of stories, and ground motion intensity are the major factors affecting the story displacement equations. Hence, he suggested that the equations be a function of the aforementioned factors. Though DDBD concluded that the maximum drift occurs in the first story, the study showed this is not the case.

Amaris and Priestley [31] found that for cantilever wall buildings ranging from two to 20 stories, reducing the elastic modal force effects by the behavior factor (force-reduction factor) and produces an unsafe design. Thus, they recommended using Modified Modal Superposition (MMS). MMS combines DDBD-obtained inelastic first-mode and elastic higher-mode force effects by the Square Root of Sum Squares (SRSS) method. It gives a satisfactory result for shorter walls (four- to eight-story cases), while it is slightly conservative for taller walls (12- and 20-story cases). Priestley [32] showed that MMS should not be applied for RC frames since yielding causes a significant increase in higher-mode periods compared to walls. Higher-mode periods tend to slide down the constant velocity slope of the response spectrum. Consequently, design by MMS results in conservative responses when checked by NTHA.

When using MMS for wall-frame structures, an improved result has been attained by modifying the structure's stiffness model (Sullivan et al. [33]). NTHA showed that MMS results in desired outputs for column forces and wall shears. However, it tended to be over-conservative for wall moments. Cheng [34] derived a stiffness matrix for frame members with a plastic hinge at one or both ends using the bilinear moment-curvature relationship for the hinges. To formulate the lateral stiffness of the structure representing the beam-sway mechanism, the post-yield stiffness and initial stiffness of the plastic hinge are needed, which are obtained after the design is completed unless assumed first.

Currently, DDBD does not provide design procedures to account for torsional and higher-mode responses of plan-asymmetric RC frame buildings having a mass and stiffness irregularity along the height. In this paper, a seismic design procedure is proposed to incorporate the torsional and higher-mode responses in DDBD of plan-asymmetric buildings with the above-mentioned irregularities. Torsional responses are significantly reduced by assigning frames' lateral stiffness so that eccentricity between centers of supported mass and rigidity is eliminated. Once this task is performed, higher-mode responses are included by a design procedure developed by Abebe and Lee [35] for planar frame buildings. In their paper, an equivalent lateral secant stiffness of a building responding in its nonlinear range is determined. Using the stiffness, elastic higher-mode responses can be obtained which are superposed to DDBD's inelastic first-mode responses. The case studies designed as such do not exceed the allowable performance levels when checked by NTHA, thus fulfilling the desired performance objectives. Ultimately, the goal of the proposed method is to render design verification by NTHA less mandatory though more case studies should be investigated.

\section{The Proposed Seismic Design Procedure for Plan-Asymmetric RC Frame Buildings}

A seismic design procedure is proposed for plan-asymmetric buildings to alleviate the shortcomings of DDBD. The main tasks undertaken are the following:

(1) Assigning moment of inertia reduction factors for members of frames so that the center of rigidity and center of supported mass coincide. 
(2) Scaling the moment of inertia reduction factors so that the allowable story displacements, drifts, and plastic hinge rotations are not exceeded.

(3) Determining elastic higher-mode force effects that are combined with DDBD-obtained force effects. The buildings' stiffness modified according to tasks (1) and (2) is used for modal analysis. Design can then be performed for the modal superposed lateral force effects, P- $\Delta$ forces, and gravity loading.

Before applying the proposed procedure, member dimensions are assumed and gravity loads are determined. A given performance objective is chosen, which the building must fulfill under specified seismic hazard levels anticipated at the building site. With the above data obtained, the steps to be followed are given below. A flowchart is provided to show a brief outline of the steps as given below (Figure 1). In this study, uni-directional ground motions in the $y$-direction (Figure 2) are applied and responses checked.

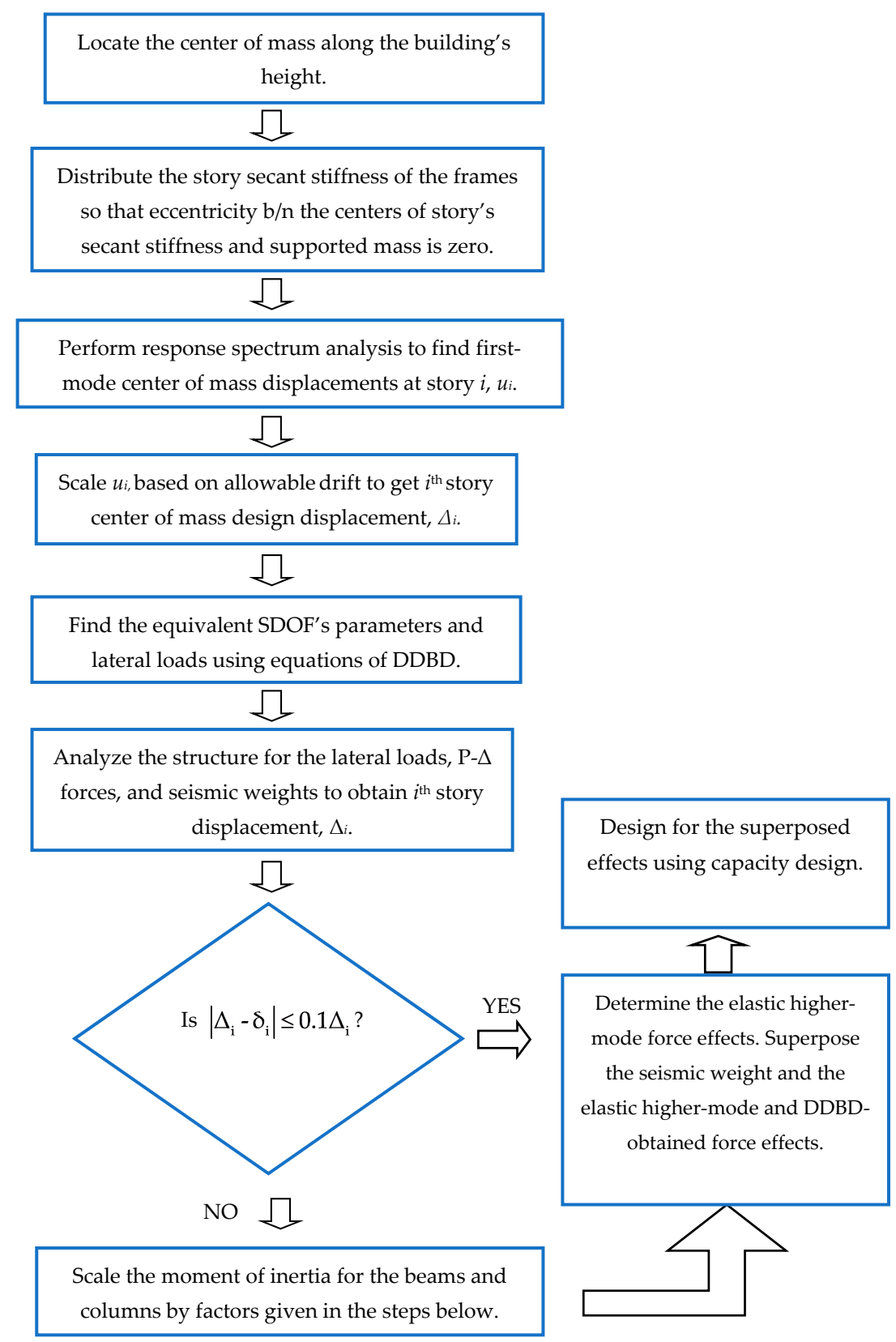

Figure 1. Flowchart for the proposed seismic design procedure accounting for higher-mode and torsional effects. 


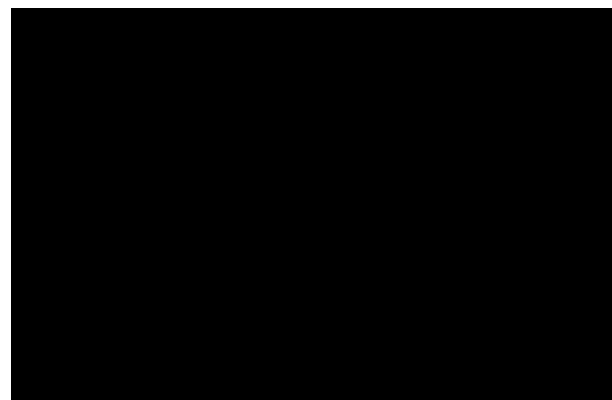

Figure 2. $k$-th story plan view.

(Step 1) Consider the plan view of a given building at the $k$-th story as shown in Figure 2. Using Equation (1), calculate the $x$-coordinate's location of the $k$-th story center of supported mass, $x_{c m, k}$.

$$
x_{c m, k}=\frac{\sum_{i=k}^{n} m_{i} x_{m i}}{\sum_{i=k}^{n} m_{i}}
$$

where $m_{i}$ is the mass at story $i, x_{m, i}$, the $x$-coordinate of the center of mass at story $i$, and $n$ represents the total number of stories.

(Step 2) Equation (2) is developed by Smith et al. [36] to determine the lateral stiffness of a given frame at story $k, K_{k}$.

$$
K_{k}=\frac{12 E_{c} / s_{k}^{2}}{\sum_{i=1}^{b}\left(I_{g b} / l_{b}\right)_{i}}+\frac{1}{\sum_{i=1}^{c}\left(I_{g c} / s_{k}\right)_{i}}
$$

where $E_{c}$ is the young modulus of the concrete material, $s_{k}$ is the $k$-th-story height, and $l_{b}$ is the beam's span length. $b$ and $c$ represent the number of beams and columns in story $k$, respectively. $I_{g b}$ and $I_{g c}$ are the gross moment of inertia for beams and columns, respectively. To determine the $x$-coordinate of the center of rigidity at story $k$ of a building in nonlinear range, $x_{c r, k}$, Equation (3) is used.

$$
x_{c r, k}=\frac{\sum_{j=1}^{m} K_{j, k} x_{j}}{\sum_{j=1}^{m} K_{j, k}}=\frac{\sum_{j=1}^{m} \gamma_{j, k} K_{r e f, k} x_{j}}{\sum_{j=1}^{m} \gamma_{j, k} K_{r e f, k}}
$$

where $K_{j, k}=\gamma_{j, k} K_{r e f, k} . K_{r e f, k}$ is the secant lateral stiffness of a reference frame at story $k$. A reference frame is preferably chosen arbitrarily, which rises to the top of the building roof. Figure 2 shows that frame $\mathrm{A}$ is a reference frame while its elevation view is depicted in Figure 3. The $k$-th story secant stiffness for the reference frame is determined by substituting $I_{g b}$ with $\alpha_{b} I_{g b}$ and $I_{g c}$ with $\alpha_{c} I_{g c}$ (for the first-story column only). $\alpha_{b}$ and $\alpha_{c}$ are the moment of inertia reduction factors for beams and columns, respectively. $x_{j}$ is the $x$-coordinate for frame $j . \gamma_{j, k}$ is a factor assigned to the $j$-th frame to relate the frame to the reference frame secant stiffness at story $k . \gamma_{r e f, k}$, is clearly 1 , and $m$ stands for the number of frames at story $k$.

To eliminate the out-of-plane torsional floor rotation at story $k$, the in-plane stiffness eccentricity at story $k, e_{x, k}$, given by Equation (4) below, is set to zero.

$$
e_{x, k}=\left|x_{c r, k}-x_{c m, k}\right| .
$$

Accordingly, $\gamma_{j, k}$ values are chosen so that $e_{x, k}$ will be zero. To minimize strength difference between frames and result in insignificant torsional rotation, $m-2$ frames are assigned arbitrary $\gamma_{j, k}$ values that range from 0.7 to 1.2 . Thus, torsion will not impose high displacement demand to frames 
far from the supported mass center compared to those near it. One-frame relative stiffness value for story $k, \gamma_{1, k}$, is calculated by setting Equation (5) to zero and, can have a value other than a value between 0.7 to 1.2 .

If the origin is taken from the $x$-coordinate of the center of supported mass, $e_{x, k}$ will be equal to $x_{c r, k}$. Setting $x_{c r, k}$ to zero as in Equation (5) and letting $x_{j}^{\prime}$ be the $x$-coordinate from the center of supported mass to the frame $j, \gamma_{1, k}$ can be determined.

$$
\frac{\sum_{j=1}^{m} \gamma_{j, k} K_{r e f, k} x_{j}^{\prime}}{\sum_{j=1}^{m} \gamma_{j, k} K_{r e f, k}}=0 \Rightarrow \frac{\sum_{j=1}^{m} \gamma_{j, k} x_{j}^{\prime}}{\sum_{j=1}^{m} \gamma_{j, k}}=0 \Rightarrow \sum_{j=1}^{m} \gamma_{j, k} x_{j}^{\prime}=0 .
$$

For frames closer to the center of supported mass, lower values of the range can be used and vice versa. When a negative value is obtained in calculating the $\gamma_{1, k}$, the range can be adjusted until a positive value is found. The relative stiffness values can vary along the height following the variation of the center of supported mass location. In that case, average relative stiffness values can be used for values within a ten percent variation in a given consecutive story range.

Typically, some frames have fewer columns and beams than other frames in a given story. For example, in Figure 2, frame A has two columns and one beam while frame J has three columns and two beams. In this case, an adjustment is needed.

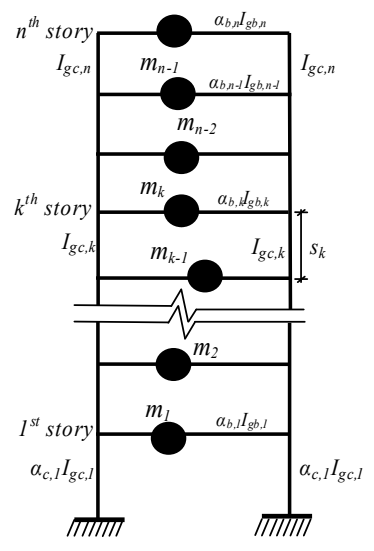

(a)

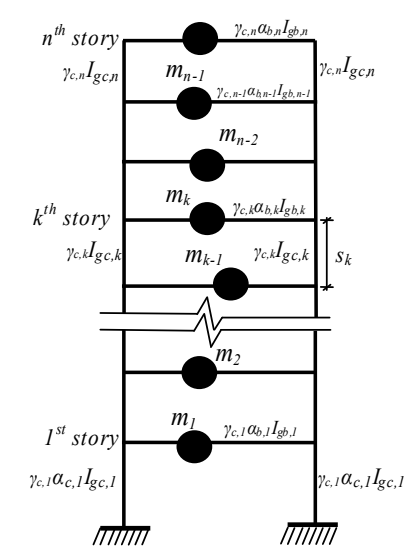

(b)

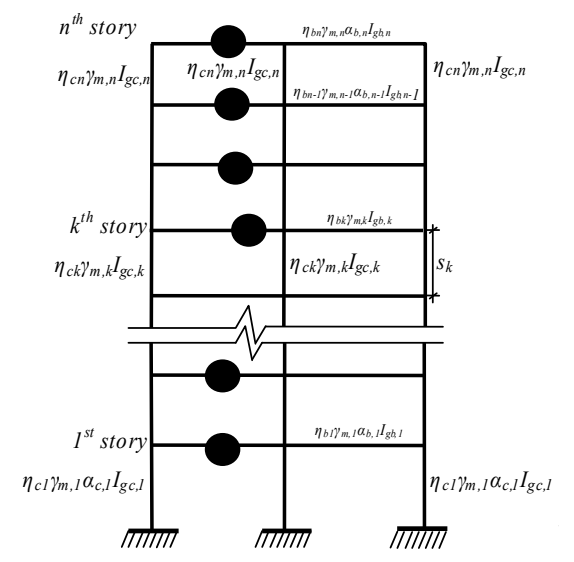

(c)

Figure 3. (a) Reference frame (Frame A). (b) Frame B. (c) J-th frame.

The $k$-th-story's lateral stiffness for the $j$-th frame and the reference frame can be equal if factors $\eta_{b k}$ and $\eta_{c k}$ are used for the $j$-th frame as follows:

$$
\frac{12 E_{c, \text { ref }} / s_{k}^{2}}{\frac{1}{\sum_{i=1}^{b_{\text {ref }}}\left(I_{g b, r e f} / l_{b, r e f}\right)_{i}}+\frac{1}{\sum_{i=1} \sum_{\text {ref }}\left(I_{g c, r e f} / s_{k}\right)_{i}}}=\frac{12 E_{c, j} / s_{k}^{2}}{\frac{1}{\eta_{b k} \sum_{i=1}^{b_{j}}\left(I_{g b, j} / l_{b, j}\right)_{i}}+\frac{1}{\eta_{c k} \sum_{i=1}^{c_{j}}\left(I_{g c, j} / s_{k}\right)_{i}}}
$$

where $I_{g b, r e f}$ and $I_{g c, \text { ref }}$ are the gross moment of inertia for beams and columns of the reference frame at story $k$, respectively. $I_{g b, j}$ and $I_{g c, j}$ are the gross moment of inertia for beams and columns of the $j$-th frame at story $k$, respectively. $l_{b, r e f}$ and $l_{b, j}$ are the beam span for the reference and $j$-th frame at story $k$, respectively. $b_{\text {ref }}$ and $c_{\text {ref }}$ represent the number of beams and columns in story $k$ for the reference frame, respectively. $b_{j}$ and $c_{j}$ represent the number of beams and columns in story $k$ for the $j$-th frame, respectively. If $E_{c, r e f}=E_{c, j}$, then 


$$
\frac{1}{\eta_{b k} \sum_{i=1}^{b_{j}}\left(I_{g b, j} / l_{b, j}\right)_{i}}+\frac{1}{\eta_{c k} \sum_{i=1}^{c_{j}}\left(I_{g c, j} / s_{k}\right)_{i}}=\frac{1}{\sum_{i=1}^{b_{r e f}}\left(I_{g b, r e f} / l_{b, r e f}\right)_{i}}+\frac{1}{\sum_{i=1}^{c_{r e f}}\left(I_{g c, r e f} / s_{k}\right)_{i}} .
$$

Keeping the equality of the left and right sides of Equation (7) and after simple algebraic manipulation,

$$
\begin{array}{r}
\eta_{b k}=\frac{\sum_{i=1}^{b_{\text {ref }}}\left(I_{g b, r e f} / l_{b, r e f}\right)_{i}}{\sum_{i=1}^{b_{j}}\left(I_{g b, j} / l_{b, j}\right)_{i}} \\
\eta_{c k}=\frac{\sum_{i=1}^{c_{r e f}}\left(I_{g c, r e f} / s_{k}\right)_{i}}{\sum_{i=1}^{c_{j}}\left(I_{g c, j} / s_{k}\right)_{i}} .
\end{array}
$$

Determine the factors $\gamma, \eta_{b}$ and $\eta_{c}$ at all stories for all frames in the $y$-direction. Frames in the $x$-direction are unchanged. There is no need to calculate the actual value of the story's secant stiffness for any of the elements. The factors $\alpha_{b}$ and $\alpha_{c}$ along with $\gamma, \eta_{b}$ and $\eta_{c}$ can be input as section property modifiers in the analysis software, in this case, SAP 2000 V.18. Steps 1 and 2 significantly reduce torsional responses and result in predominantly translational motion of the plan-asymmetric buildings. The next steps to be followed are almost the same as the Steps 2 to 9 of the proposed method developed by Abebe and Lee [35] that considers higher-mode effects in planar RC frames. The only difference is that instead of using design displacement at each story of the frames, the design displacement at the center of mass location of a floor is used. The steps are reproduced here for convenience.

(Step 3) Conduct a modal analysis to calculate the first-mode displacement, $u_{i}$, at the center of mass of the story $i$ in the $y$-direction using Equation (10).

$$
u_{i}=\phi_{i} \Gamma_{1} D_{1}
$$

where $\phi_{i}$ is the first-mode shape at the center of mass of $i$-th story in $y$-direction. $\Gamma_{1}$ is the corresponding first-mode modal participation factor. $D_{1}$ is the first-mode spectral displacement for the mean displacement response spectrum of the selected ground motions obtained using an elastic damping ratio (i.e., 5 percent).

(Step 4) Determine design displacement, $\Delta_{i}$, at the center of mass of story $i . \Delta_{i}$ is found by scaling $u_{i}$ so that the allowable story drift, $\theta$, is not exceeded. $\Delta_{i}$ is given as Equation (11).

$$
\Delta_{i}=u_{i}^{*} \min \left\{\frac{\theta s_{j}}{u_{j}-u_{j-1}}\right\}
$$

where $u_{j}$ and $u_{j-1}$ are the first-mode displacements at the center of mass location of story $j$ and $j-1$, respectively. $s_{j}$ is the $j$-th story height. $j=1,2,3, \ldots, n . n$ stands for the number of stories.

(Step 5) Calculate the effective mass, $m_{\text {eff, }}$ effective height, $h_{\text {eff, }}$ design displacement at effective height, $\Delta_{d}$, average yield rotation, $\theta_{y, a v g}$, yield displacement at effective height, $\Delta_{y}$, ductility at $\Delta_{d}$, $\mu$, equivalent viscous damping ratio, $\xi_{\text {eq }}$, effective period, $T_{\text {eff, }}$, base shear for the first-mode, $V_{b}$, and lateral force at story $i$-th, $F_{i}$, using equations of DDBD as provided by Priestley et al. [37]. These equations are also provided in Appendix A below. Using SeismoSpect 2016 [38], the displacement response spectra for the equivalent viscous damping ratios can be plotted. 
(Step 6) Find $\delta_{i}$, the output displacement at the center of mass in the $y$-direction obtained using a linear analysis of the structural model modified as Step 2. The loading applied includes $F_{i}$, the seismic weight, and the additional lateral force due to P- $\Delta, Q_{i}$. MacGregor et al. [39] derived $Q_{i}$ as follows:

$$
Q_{i}=\frac{P_{i} \Delta_{i}}{s_{i}}-\frac{P_{i+1} \Delta_{i+1}}{s_{i+1}}
$$

where $P_{i}$ is the sum of story seismic weights at the $i$-th level and above $i . s_{i}$ is the $i$-th story height.

(Step 7) Update the structural model's secant stiffness given in Step 2 by setting a new moment of inertia reduction factor for beams, $\alpha^{\prime}{ }_{b}$, and for columns, $\alpha^{\prime}{ }_{c}$, as in Equation (13) if $\left|\Delta_{i}-\delta_{i}\right|>0.1 \Delta_{i}$ where $i=1,2,3, \ldots, n . n$ is the number of stories

$$
\alpha_{b}^{\prime}=\alpha_{b} \frac{\sum_{i=1}^{n}\left\{\delta_{i} / \Delta_{i}\right\}}{n} ; \alpha_{c}^{\prime}=\alpha_{c} \frac{\sum_{i=1}^{n}\left\{\delta_{i} / \Delta_{i}\right\}}{n} .
$$

The factor multiplying $\alpha_{b}$ and $\alpha_{c}$ in Equation (13) is found to yield a reasonable estimate of design story displacements. It is based on the linear force-displacement relation, whereby keeping the force equal, desired displacements can be obtained by scaling the stiffness. It is known that multiplying a stiffness matrix by a factor does not change the first-mode shapes, $\phi_{i}$, and first-mode modal participation factor, $\Gamma_{1}$. Though the first-mode spectral displacement, $D_{1}$, changes as the first-mode period varies, it cancels out from Equation (11). Hence, the design displacements, $\Delta_{i}$, and the story lateral forces, $F_{i}$, remain unaltered. If so,

$$
\left\{F_{i}\right\}=\left[K_{\text {initial }}\right]\left\{\delta_{i}\right\}=\left[K_{\text {final }}\right]\left\{\Delta_{i}\right\}
$$

and for multi-story frames, $\left[K_{\text {final }}\right]$ is approximated as in Equation (15)

$$
\left[K_{\text {final }}\right] \approx\left[K_{\text {initial }}\right] \frac{\sum_{i=1}^{n}\left\{\delta_{i} / \Delta_{i}\right\}}{n}
$$

where $i=1,2,3, \ldots, n$. $n$ is the number of stories. [ $\left.K_{\text {initial }}\right]$ is the secant stiffness matrix of the frames with $I_{g b}$ and $I_{g c}$ modified by $\alpha_{b}, \alpha_{c}, \gamma, \eta_{b}$ and $\eta_{c}$, respectively. [K $\left.K_{\text {final }}\right]$ will then be approximated as the final secant stiffness matrix with $I_{g b}$ and $I_{g c}$ modified by $\alpha_{b}^{\prime}$ and $\alpha_{c}^{\prime}, \gamma, \eta_{b}$ and $\eta_{c}$, respectively.

(Step 8) Calculate the force effects by linear analysis applying $F_{i}$ on the structural model modified in Step 7.

(Step 9) Determine the elastic higher-mode force effects for the modes contributing to at least 90 percent of the total mass. Using the SRSS method, combine force effects from Step 8 and the elastic higher-mode force effects. SRSS is used since the modal frequencies are well separated, i.e., the adjacent frequencies have a ratio of greater than 2 or less than 0.5. In addition, translational motion of each frame is expected which allows the use of SRSS modal combination. Superpose the force effects from the seismic weight, P- $\Delta$ forces, and the modal-combined lateral force effects to get design force effects. SAP2000 V.18 has been used for the purpose of structural analysis.

(Step 10) Employ capacity design to achieve the beam-sway mechanism. For a plastic hinge location, the expected material strength is used while the strength reduction factor is set as unity (Priestley et al. [37]). At other column locations, design moments, $M_{D}$, are calculated as follows:

$$
\varphi_{s} M_{D} \geq \varphi^{o} M_{A}
$$

where $\varphi_{S}$ is the strength reduction factor, $\varphi^{o}$ is an over-strength factor and $M_{A}$ is the applied moment. 


\section{Numerical Examples}

To investigate the performance of the proposed design procedure, two plan-asymmetric 20-story RC frame buildings are chosen. Ali et al. [40] stated that moment-resisting frames will be ineffective in resisting seismic loading above the 20-story limit. Hence, the case studies are imposed on this recommendation. Case-I has same-plan configuration while Case-II has different-plan configuration along the height. Both cases have different bay widths in orthogonal directions as shown in Figures 4 and 5. Columns and beams have dimensions of $800 \mathrm{~mm} \times 800 \mathrm{~mm}$ and $800 \mathrm{~mm} \times 300 \mathrm{~mm}$, respectively, for all stories for the frames in the $y$-direction. In the $x$-direction, the beam dimensions are $500 \mathrm{~mm} \times 300 \mathrm{~mm}$ for all stories. All stories are $3.5 \mathrm{~m}$ high. The seismic load acting on all beams is $15 \mathrm{kN} / \mathrm{m}$, excluding the frame members' weight. A characteristic cylinder strength, $f^{\prime}{ }_{c}$, of $30 \mathrm{MPa}$ for the concrete, a characteristic yield strength of $413.7 \mathrm{MPa}$, and an ultimate strength of $620.5 \mathrm{MPa}$ for the rebar are used. The characteristic concrete and rebar strengths are factored by 1.3 and 1.1, respectively, to obtain the corresponding expected material strengths.

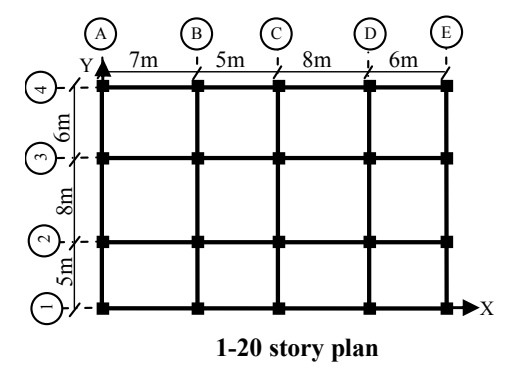

Figure 4. Case-I's plan view.

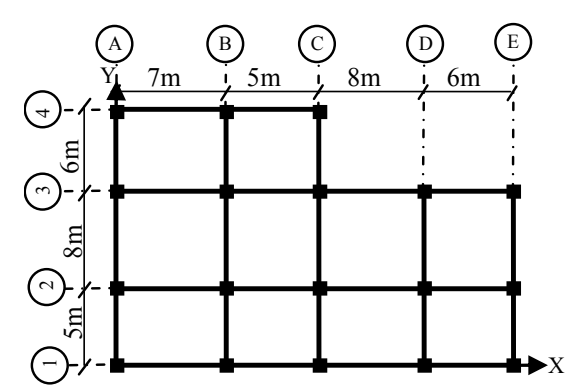

(a)

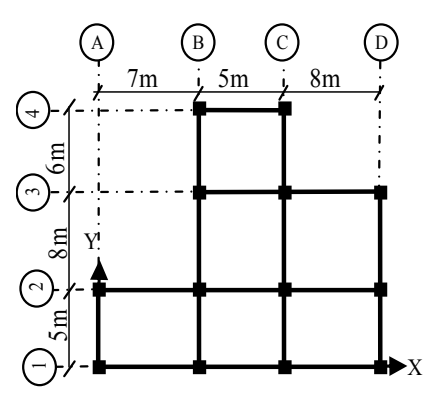

(b)

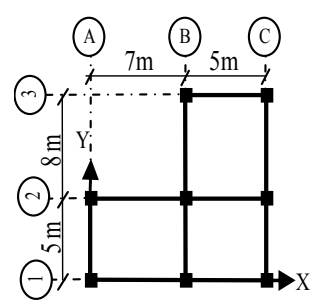

(c)

Figure 5. Case-II's plan view for (a) 1st-5th story plan; (b) 6th-13th story plan; (c) 14th-20th story plan.

In this study, it is desired that a basic safety objective must be fulfilled according to the Federal Emergency Management Agency (FEMA-356) standard [41]. Therefore, the buildings when subjected to Design Basis Earthquake (DBE) and Maximum Considered Earthquake (MCE) hazard levels, the Life Safety (LS) and Collapse Prevention (CP) performance levels were not exceeded, respectively. To achieve the performance levels LS and CP, the mean NTHA story drifts shall not be higher than 2 percent and 4 percent, respectively (Table C1-3 of FEMA 356). Mean NTHA plastic hinge rotations shall not exceed the allowable FEMA 356 plastic hinge rotations (Tables 6.8 and 6.9 of FEMA 356).

The case studies are located near San Andreas Fault having coordinates of $37^{\circ} \mathrm{N},-122^{\circ} \mathrm{W}$. Class C (very dense soil and soft rock) is assumed for the soil type. The U.S. seismic design map is utilized to obtain the site's design spectral accelerations, $S_{d 1}$ and $S_{d s}$, and long period, $T_{L}$. These values are input in the PEER NGA-West 2 ground motion database [42] to generate the acceleration response spectrum for DBE. The acceleration response spectrum for MCE is 1.5 times the acceleration response spectrum for DBE. Again, the PEER NGA-West 2 ground motion database is used to select and scale eleven ground motions (Tables 1 and 2) to match the 5-percent damping DBE and MCE acceleration response spectra (Figure $6 a, b)$. 
Table 1. Selected ground motions for Design Basis Earthquake (DBE).

\begin{tabular}{|c|c|c|c|c|c|c|c|c|c|c|}
\hline $\begin{array}{l}\text { Result } \\
\text { ID }\end{array}$ & Earthquake Name & Station Name & $\begin{array}{l}\text { Magnitude } \\
\left(\mathbf{M}_{\mathrm{w}}\right)\end{array}$ & Mechanism & $\begin{array}{l}\text { Peak Ground } \\
\text { Accelartion (g) }\end{array}$ & $\begin{array}{l}\text { Scale } \\
\text { Factor }\end{array}$ & $\begin{array}{l}\text { Tp-Pulse } \\
\text { Period (s) }\end{array}$ & $\begin{array}{l}\text { Arias Intensity } \\
(\mathrm{m} / \mathrm{s})\end{array}$ & $\begin{array}{l}\text { Vs30 } \\
(\mathrm{m} / \mathrm{s})\end{array}$ & $\begin{array}{c}5-95 \% \\
\text { Duration (s) }\end{array}$ \\
\hline 1 & “Tabas_Iran" & "Boshrooyeh" & 7.35 & Reverse & 0.389 & 3.7211 & - & 0.3 & 324.57 & 19.5 \\
\hline 2 & "Tabas_Iran" & "Tabas" & 7.35 & Reverse & 0.439 & 0.5323 & 6.188 & 11.8 & 766.77 & 16.5 \\
\hline 3 & "Cape Mendocino" & "Fortuna-Fortuna Blvd" & 7.01 & Reverse & 0.392 & 2.8713 & - & 0.3 & 457.06 & 18.7 \\
\hline 4 & "Landers" & "North Palm Springs" & 7.28 & strike slip & 0.477 & 3.509 & - & 0.7 & 344.67 & 37.9 \\
\hline 5 & “Landers" & "Yermo Fire Station" & 7.28 & strike slip & 0.347 & 1.5334 & 7.504 & 0.9 & 353.63 & 18.9 \\
\hline 6 & "Kocaeli_Turkey" & "Arcelik" & 7.51 & strike slip & 0.813 & 3.7339 & 7.791 & 0.3 & 523 & 11.1 \\
\hline 7 & "Kocaeli_Turkey" & “Duzce" & 7.51 & strike slip & 0.377 & 1.1602 & - & 1.3 & 281.86 & 11.8 \\
\hline 8 & "Kocaeli_Turkey" & "Gebze" & 7.51 & strike slip & 0.392 & 1.7377 & 5.992 & 0.5 & 792 & 8.2 \\
\hline 9 & "Chi-Chi_Taiwan" & “CHY006" & 7.62 & $\begin{array}{l}\text { Reverse } \\
\text { Oblique }\end{array}$ & 0.438 & 1.3398 & 2.5704 & 2 & 438.19 & 26.7 \\
\hline 10 & “Chi-Chi_Taiwan” & “CHY010” & 7.62 & $\begin{array}{l}\text { Reverse } \\
\text { Oblique }\end{array}$ & 0.458 & 2.5821 & - & 0.7 & 538.69 & 29.8 \\
\hline 11 & "Chi-Chi_Taiwan" & “CHY024" & 7.62 & $\begin{array}{l}\text { Reverse } \\
\text { Oblique }\end{array}$ & 0.356 & 1.2285 & 6.65 & 1.8 & 427.73 & 27 \\
\hline
\end{tabular}

Table 2. Selected ground motions for Maximum Considered Earthquake (MCE).

\begin{tabular}{|c|c|c|c|c|c|c|c|c|c|c|}
\hline $\begin{array}{l}\text { Result } \\
\text { ID }\end{array}$ & Earthquake Name & Station Name & $\begin{array}{c}\text { Magnitude } \\
\left(\mathbf{M}_{\mathrm{w}}\right)\end{array}$ & Mechanism & $\begin{array}{l}\text { Peak Ground } \\
\text { Accelartion (g) }\end{array}$ & $\begin{array}{l}\text { Scale } \\
\text { Factor }\end{array}$ & $\begin{array}{l}\text { Tp-Pulse } \\
\text { Period (s) }\end{array}$ & $\begin{array}{l}\text { Arias Intensity } \\
(\mathrm{m} / \mathrm{s})\end{array}$ & $\begin{array}{l}\text { Vs30 } \\
(\mathrm{m} / \mathrm{s})\end{array}$ & $\begin{array}{c}5-95 \% \\
\text { Duration (s }\end{array}$ \\
\hline 1 & “Tabas_Iran" & "Boshrooyeh" & 7.35 & Reverse & 0.613 & 5.8633 & - & 0.3 & 324.57 & 19.5 \\
\hline 2 & "Tabas_Iran" & "Tabas" & 7.35 & Reverse & 0.699 & 0.848 & 6.188 & 11.8 & 766.77 & 16.5 \\
\hline 3 & "Cape Mendocino" & "Fortuna-Fortuna Blvd" & 7.01 & Reverse & 0.589 & 4.3161 & - & 0.3 & 457.06 & 18.7 \\
\hline 4 & "Landers" & "Yermo Fire Station" & 7.28 & strike slip & 0.512 & 2.2642 & 7.504 & 0.9 & 353.63 & 18.9 \\
\hline 5 & "Kocaeli_Turkey" & “Arcelik" & 7.51 & strike slip & 1.207 & 5.5465 & 7.791 & 0.3 & 523 & 11.1 \\
\hline 6 & "Kocaeli_Turkey" & "Duzce" & 7.51 & strike slip & 0.584 & 1.7334 & - & 1.3 & 281.86 & 11.8 \\
\hline 7 & "Kocaeli_Turkey" & "Gebze" & 7.51 & strike slip & 0.578 & 2.5618 & 5.992 & 0.5 & 792 & 8.2 \\
\hline 8 & "Chi-Chi_Taiwan" & "CHY006" & 7.62 & $\begin{array}{l}\text { Reverse } \\
\text { Oblique }\end{array}$ & 0.692 & 2.1178 & 2.5704 & 2 & 438.19 & 26.7 \\
\hline 9 & “Chi-Chi_Taiwan" & “CHY010" & 7.62 & $\begin{array}{l}\text { Reverse } \\
\text { Oblique }\end{array}$ & 0.709 & 4.0024 & - & 0.7 & 538.69 & 29.8 \\
\hline 10 & "Chi-Chi_Taiwan" & "CHY024" & 7.62 & $\begin{array}{l}\text { Reverse } \\
\text { Oblique }\end{array}$ & 0.534 & 1.8426 & 6.65 & 1.8 & 427.73 & 27 \\
\hline 11 & "Chi-Chi_Taiwan" & "CHY029" & 7.62 & $\begin{array}{l}\text { Reverse } \\
\text { Oblique }\end{array}$ & 0.758 & 2.7817 & - & 0.9 & 544.74 & 32.3 \\
\hline
\end{tabular}




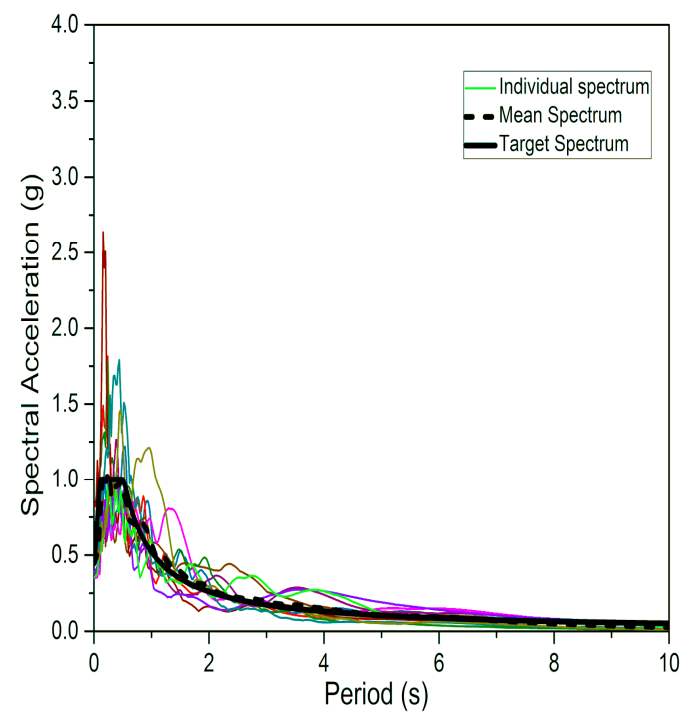

(a)

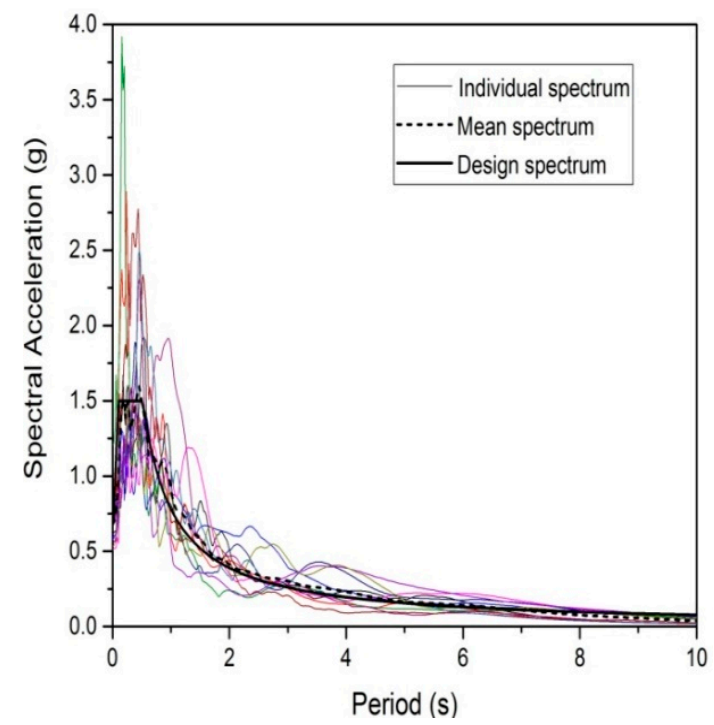

(b)

Figure 6. (a) Acceleration response spectrum for DBE. (b) Acceleration response spectrum for Maximum Considered Earthquake (MCE).

To define the secant stiffness of the case studies, the moment of inertia reduction factors, $\alpha_{b}$ for beams and $\alpha_{c}$ for first-story columns, of the reference frames need to be assumed. Kowalsky [43] and Kappos et al. [44] adopted 10 percent of the uncracked section stiffness to represent the secant stiffness of RC bridge piers as a start for their iterative design methods. Cheng [34] determined the member stiffness matrix with plastic hinges at one or both ends. Accordingly, for members with hinges at both ends, the stiffness of that member will be the stiffness based on the gross moment of inertia of members times the ratio of post-yield stiffness to the elastic stiffness of the plastic hinge. For members with only one hinge, no such simplification has been made. Thus, if that ratio is assumed as 0.1 for members with two hinges at member ends, the moment of inertia reduction factor, $\alpha_{b}$, will be also 0.1 . The values of the reduction factors are chosen arbitrarily as a starting value as it does not affect the values for $\alpha^{\prime}{ }_{c}$ and $\alpha^{\prime}{ }_{b}$. Therefore, $\alpha_{c}$ is assigned 0.3 since only one plastic hinge is expected and $\alpha_{b}$ as 0.1 or, in some cases, 0.05 . For the reference frames of the case studies, $\alpha_{c}$ is set as 0.3 , whereas $\alpha_{b}$ for the lower ten story beams is 0.1 and for the top 10 stories 0.05 . A lower value of $\alpha_{b}$ at the top stories is chosen because seismic demand reduces as the height increases.

Steps 3 to 5 need to be performed for both LS and CP levels. When using Step 5, the peak value of the mean displacement response spectra for the equivalent viscous damping may be less than the initial design displacement at effective height, $\Delta_{d \text {, initial }}$. In that case, a method discussed in Section 3.4.6(b) of Priestley et al. [37] is employed. Hence, lower final displacement, $\Delta_{d, f i n a l}$, at reduced equivalent damping ratio is found. To attain $\Delta_{d, \text { final }}$, the design story displacements need to be factored by the ratio $\Delta_{d, \text { final }} / \Delta_{d \text {, initial }}$. The DDBD base shear, $V_{b}$, for the two performance levels is compared, and the maximum is taken as a governing design base shear.

When the value of P- $\Delta$ force at story $i, Q_{i}$ is found to be negative, it is not added to the lateral force $F_{i}$ and, hence, only $F_{i}$ is taken as the design force at that story. Column design moments, $M_{D}$, are amplified by the ratio $\varphi^{\circ} / \varphi_{s}=1.2$ using $\varphi^{\circ}=1.1$ and $\varphi_{s}=0.9$. 
For Case-I, since the center of story mass and the supported mass do not vary per story, there is no variation of $\gamma$ along the height. Frame $\mathrm{A}$ is taken as a reference frame, and the relative stiffness values for frames $B, C$, and $D$ are assigned arbitrarily (Table 3). The relative stiffness value for frame $E$ is calculated using Equation (5). Correspondingly, the moment of inertia reduction factors, $\alpha_{b}$ and $\alpha_{c}$, for the frames used are shown in Table 4. From Step 9, the new moment of inertia reduction factors are 0.44 times the initial moment of inertia reduction factors. CP performance level governs for this case.

Table 3. Case-I's relative stiffness values.

\begin{tabular}{cccccc}
\hline Story & $\gamma_{A}$ & $\gamma_{B}$ & $\gamma_{C}$ & $\gamma_{D}$ & ${ }^{a} \gamma_{E}$ \\
\hline $1-20$ & 1 & 0.8 & 0.7 & 0.8 & $\approx 1$ \\
\hline \multicolumn{5}{c}{${ }^{\mathrm{a}} \gamma_{E}$ is calculated using Equation (5) by setting $e_{x, k}$ to zero. }
\end{tabular}

Table 4. Moment of inertia reduction factors for Case-I frames.

\begin{tabular}{cccccc}
\hline Reduction Factors & Frame A & Frame B & Frame C & Frame D & Frame E \\
\hline$\alpha_{b}$ for 1st-10th story & 0.1 & 0.08 & 0.07 & 0.08 & $\approx 0.1$ \\
$\alpha_{b}$ for 11th-20th story & 0.05 & 0.04 & 0.035 & 0.04 & $\approx 0.05$ \\
$\alpha_{c}$ for 1st story & 0.3 & 0.24 & 0.21 & 0.24 & $\approx 0.3$ \\
$\alpha_{c}$ for 2nd to 20th story & 1 & 0.8 & 0.7 & 0.8 & $\approx 1$ \\
\hline
\end{tabular}

For Case-II, the relative stiffness values are varied following center of supported mass variation along the height to yield $e_{x, k}$ equal to zero. Frame $\mathrm{C}$ is chosen as the reference frame (Table 5). The choice of the reference frame is arbitrary as long as the frame rises to the top-story level. The reference frame $\mathrm{C}$ is assigned $\alpha_{b}$ equal to 0.05 and 0.1 for the top ten stories and bottom ten stories, respectively. $\alpha_{c}$ is set as 0.3 . Since some frames have fewer columns and beams than others in a given story, modification per Step 2 is necessary (Table 6). $\alpha_{b}$ and $\alpha_{c}$ for frames other than the reference frame are multiples of those $\alpha_{b}$ and $\alpha_{c}$ values for frame $C$ times the factors of the frames given in Tables 5 and 6. From Step 7, the new moment of inertia reduction factors, $\alpha_{b}^{\prime}$ and $\alpha_{c}^{\prime}$, are 0.432 times the initial moment of inertia reduction factors. LS performance level governs for this case.

Table 5. Case-II's relative stiffness values.

\begin{tabular}{cccccc}
\hline Story & $\gamma_{A}$ & $\gamma_{B}$ & $\gamma_{C}$ & $\gamma_{D}$ & $\gamma_{E}$ \\
\hline $1-5$ & 1.2 & 1.1 & 1 & 1.1 & ${ }^{2} 0.03$ \\
$6-9$ & a 1.38 & 1 & 1 & 1.1 & - \\
$10-13$ & a 1.81 & 0.8 & 1 & 1.1 & - \\
$14-20$ & a 0.61 & 0.8 & 1 & - & - \\
\hline \multicolumn{6}{r}{ a Frame stiffnesses calculated using Equation (5) by setting $e_{x, k}$ to zero. }
\end{tabular}

Table 6. Modification factors, $\eta_{b}$ and $\eta_{c}$ to account for the difference in material properties, member dimensions and the number of members for Case-II frames.

\begin{tabular}{cccccc}
\hline Story & Structural Members & Frame A & Frame C (or B) & Frame D & Frame E \\
\hline \multirow{2}{*}{$1-5$} & Beams & 1 & 1 & 1.51 & 1.51 \\
& Columns & 1 & 1 & 1.33 & 1.33 \\
\hline \multirow{2}{*}{$6-13$} & Beams & 2.46 & 1 & 1.46 & - \\
& Columns & 2 & 1 & 1.5 & - \\
\hline \multirow{2}{*}{$14-20$} & Beams & 1.63 & 1 & - & - \\
& Columns & 1.5 & 1 & - & - \\
\hline
\end{tabular}




\section{Verification of the Proposed Method by NTHA}

For the NTHA of case studies, the flexural reinforcements are first calculated with the Section Designer module of SAP2000 V.18 for the design actions obtained from Step 10 of Section 2. It is required to account for the difference in rebar amount for the first-story columns' bottom end (plastic hinge) and top end. Hence, a section representing the plastic hinge is incorporated at the bottom end of the column. The section will have a rebar amount provided for the plastic hinge and a length, $L_{p}$ determined by Priestley et al. [37] as shown in Equation (17).

$$
L_{p}=k L_{c}+L_{s p}
$$

where $k=0.2\left(f_{u} / f_{y}-1\right) \leq 0.08 . L_{c}$ is the length from the plastic hinge center to the point of contra flexure in the member, and the strain penetration length $L_{s p}=0.022 f_{y e} d_{b l} . f_{u}$ and $f_{y}$ are the ultimate and yield strength of the rebar, respectively. $f_{y e}$ is the expected yield strength of the rebar in $\mathrm{MPa}$, and $d_{b l}$ is the diameter of the rebar in meters.

Nonlinear analysis for the effect of seismic weight is performed to be continued by NTHA for the ground motions. The analyses are conducted by PERFORM-3D V.7 with FEMA 356 hinges assigned to the members' ends. The floor slabs are modeled as a rigid diaphragm. The cyclic strength and stiffness degradation of the plastic hinges in PERFORM-3D is accounted for by specifying energy degradation factors. Ghodsi and Ruiz [45] provide reasonable values for the energy degradation factors. Rayleigh damping is used to model the elastic damping. A damping ratio of 5 percent is assumed at periods 1.5 and 0.1 times the fundamental period in the y-direction to calculate mass and stiffness matrix coefficients. A P- $\Delta$ option is included in the analyses.

\section{Results and Discussion}

\subsection{Case-I Building}

From NTHA outputs, it is observed that the allowable story drift of the governing performance level (i.e., 4 percent) is not exceeded for all ground motions (Figure 7). Design drifts determined from the design displacements are not exceeded when compared to the mean NTHA drifts. Mean NTHA drifts are low compared to design drifts though the mean plus one standard deviation and design drifts are approximately equal (Figure 7). The NTHA drifts tend to follow design drift profile; thus, the method produces a design that reflects the design drift (Figure 7). It is observed that NTHA drifts are nearly the same for all frames. The fact that design drifts are being exceeded for some ground motions is acceptable as long as the mean NTHA drifts from the eleven ground motions did not exceed the allowable drifts. Since the design by the proposed method is performed using the design response spectrum which corresponds to the mean response spectrum of the eleven ground motions, it is expected that some ground motions result in the design drifts being exceeded. The NTHA displacements are below the design displacements, except for one ground motion. Mean plus one standard deviation NTHA displacements are closer to the design displacements at the lower-half stories compared to the top-half stories (Figure 8). Mean NTHA displacements and drifts are almost identical for all frames (Figure 9). For example, the difference in 20th-story mean NTHA displacements at the extreme frames A and E is 0.35 percent. This signifies that the proposed method works well for plan-asymmetric buildings when the plan configuration is identical throughout the height. 


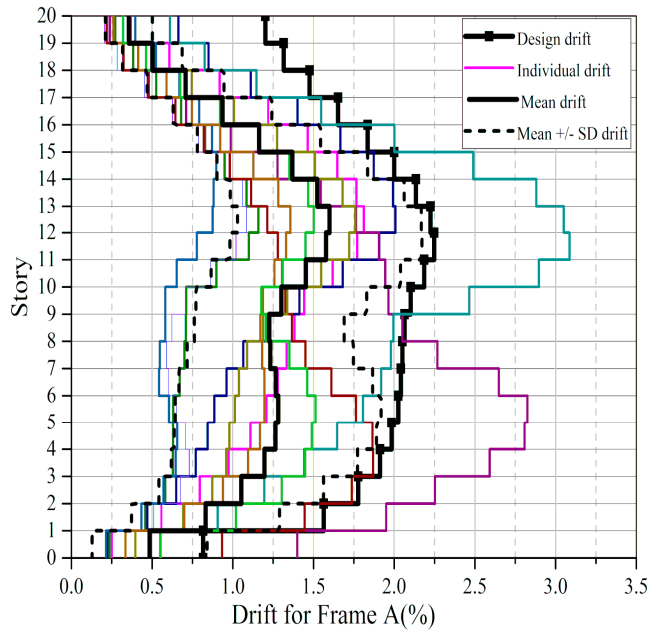

(a)

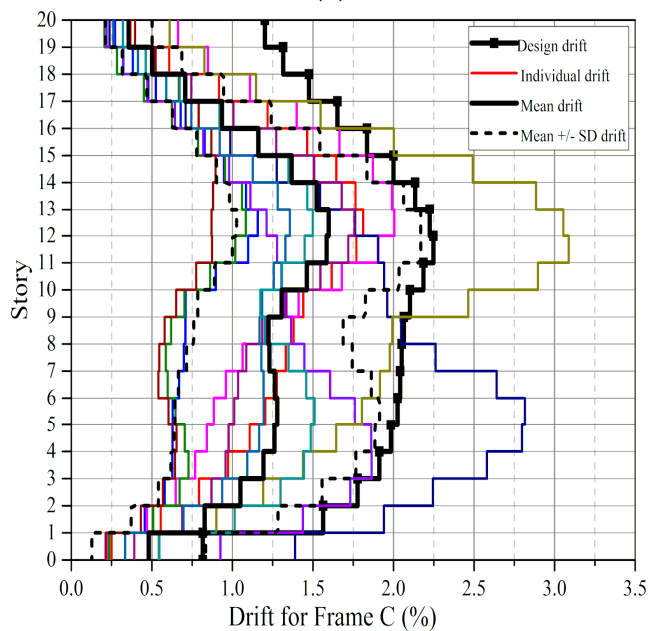

(c)

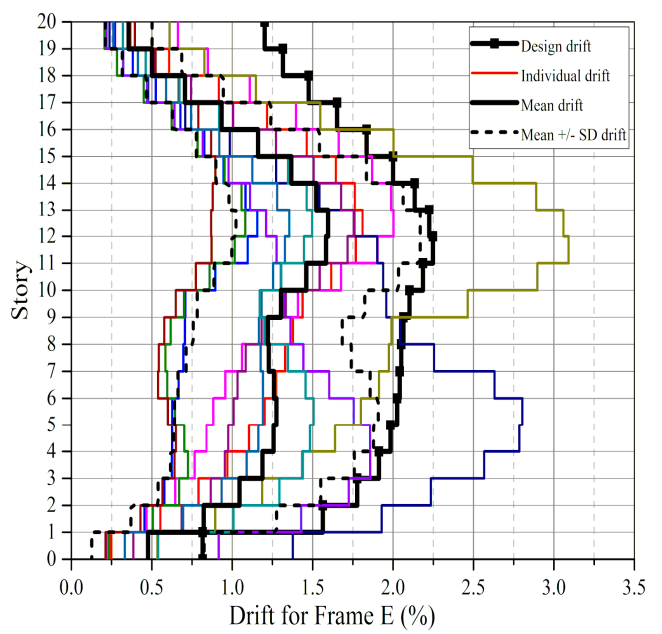

(e)

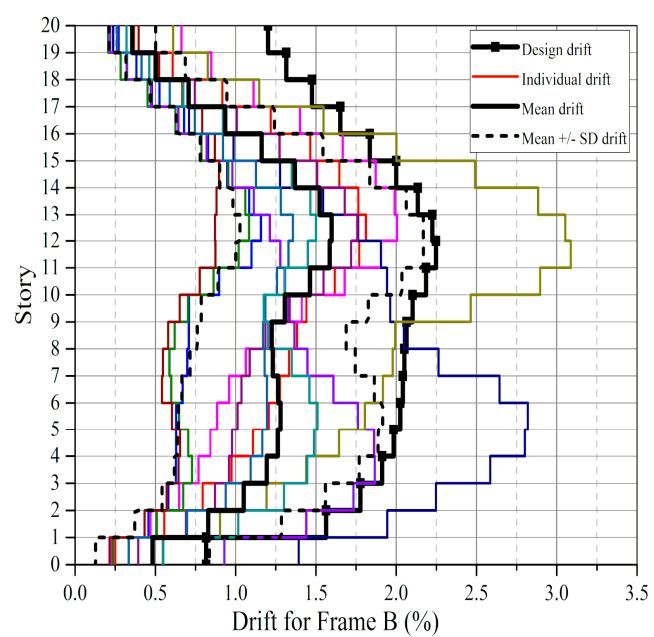

(b)

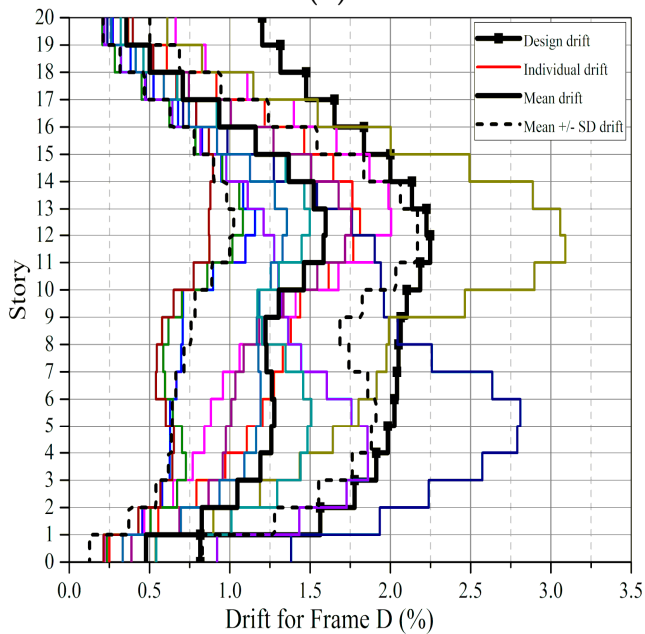

(d)

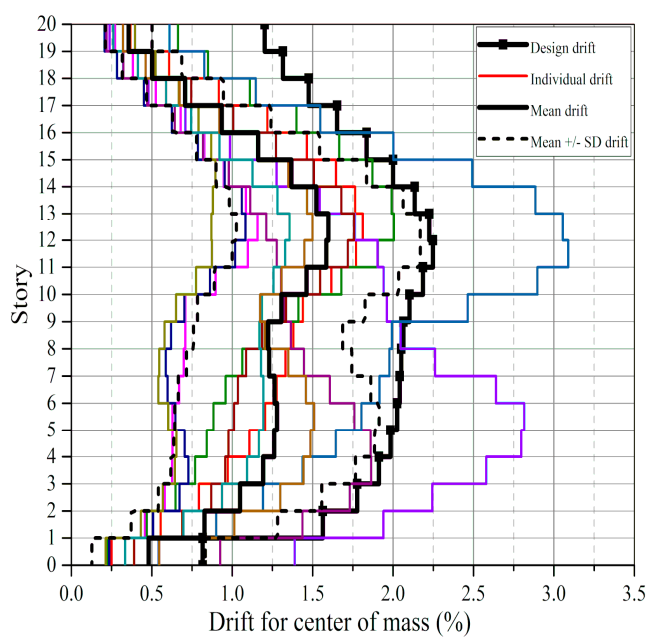

(f)

Figure 7. Case-I drift. (a) Case-I frame A's drift; (b) Case-I frame B's; (c) Case-I frame C's drift; (d) Case-I frame D's drift; (e) Case-I frame E's drift; (f) Case-I center of mass's drift. 


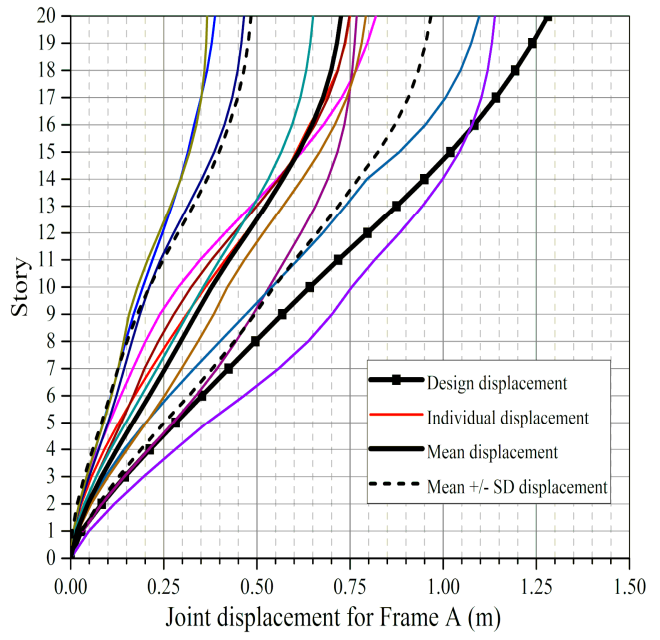

(a)

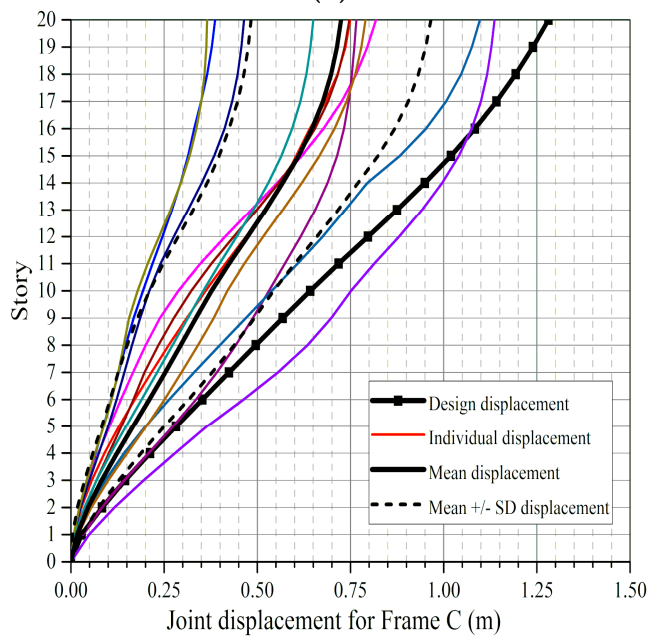

(c)

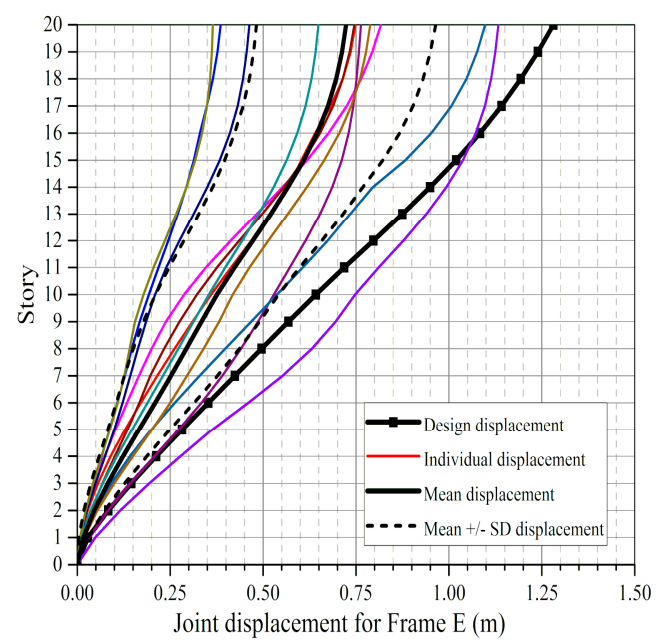

(e)

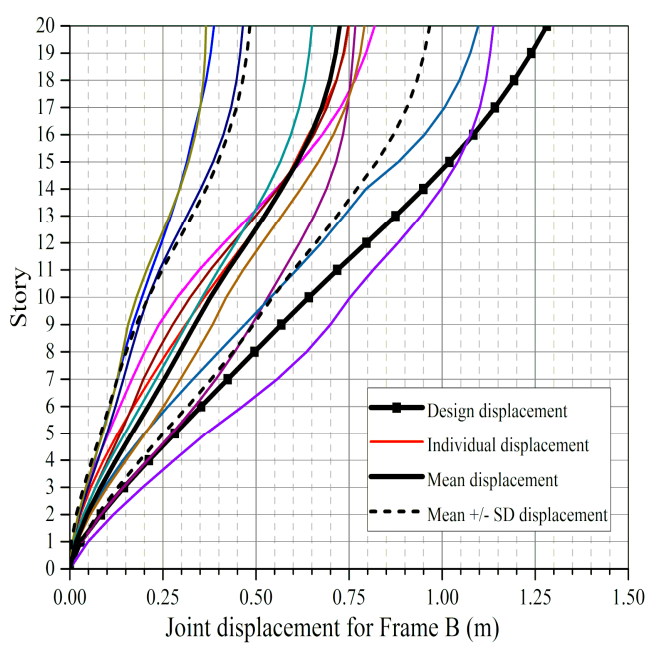

(b)

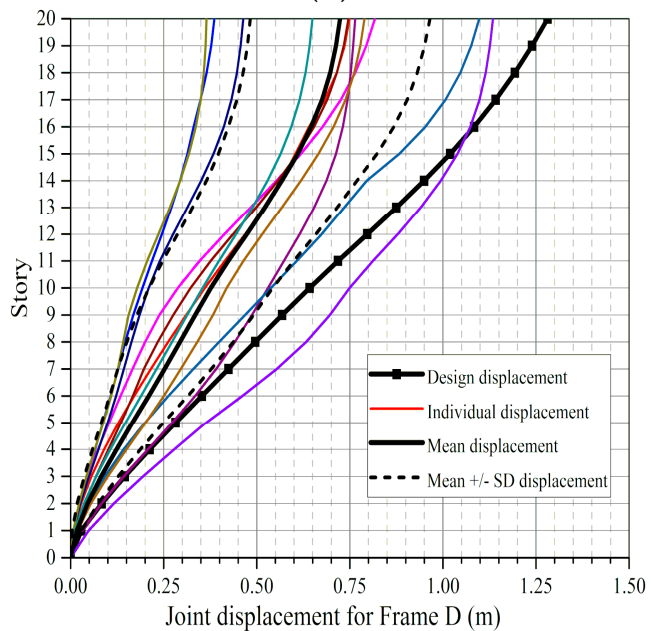

(d)

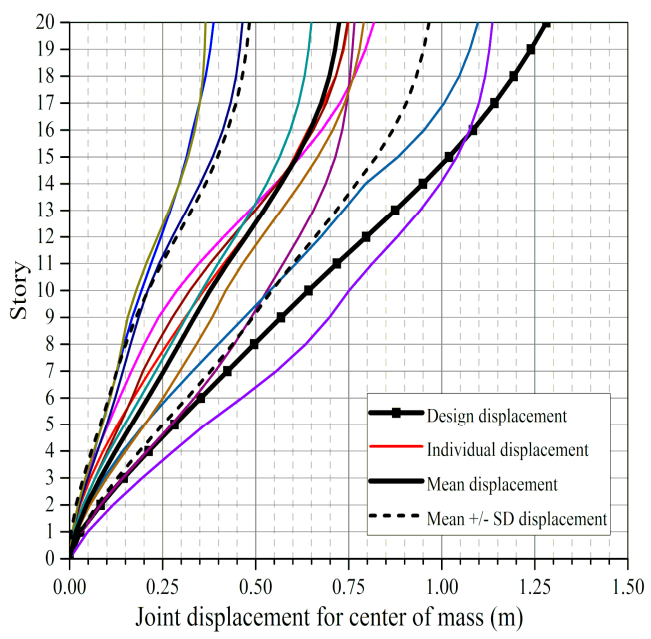

(f)

Figure 8. Case-I story's displacements. (a) Case-I frame A's displacement; (b) Case-I frame B's displacement; (c) Case-I frame C's displacement; (d) Case-I frame D's displacement; (e) Case-I frame E's displacement; (f) Case-I center of mass's displacement. 


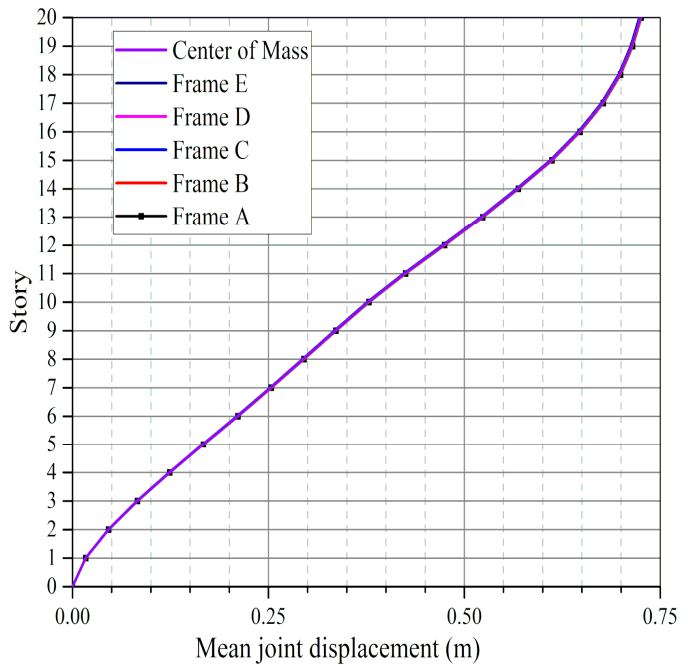

(a)

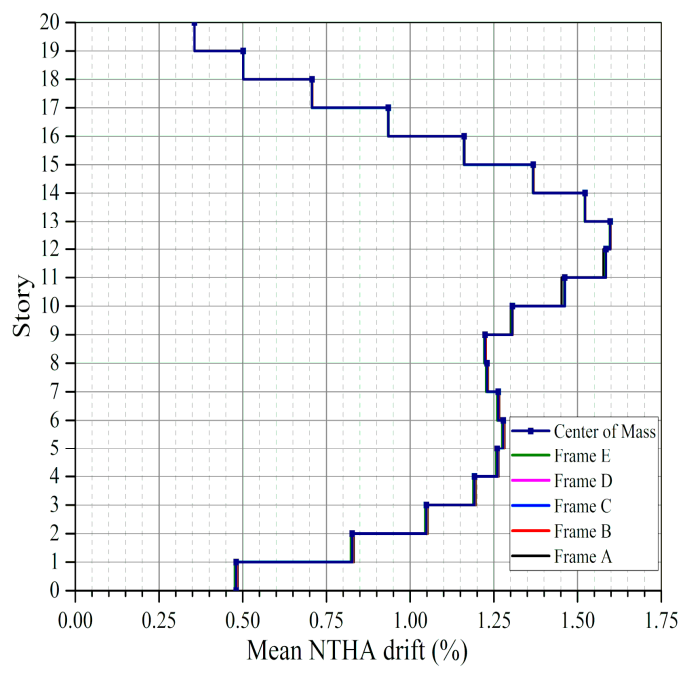

(b)

Figure 9. (a) Mean story displacement for Case-I; (b) Mean drifts for Case-I.

To check whether allowable hinge rotations for the $\mathrm{CP}$ performance level are exceeded, usage ratio graphs of Perform-3D V.7 are used. Usage ratio graphs depict the ratio of hinge rotation demand of the ground motions to the allowable hinge rotation through time. An average of 0.8 is achieved for the beams' usage ratio as shown in Figure 10a-c. For the columns' usage ratio an average of 0.2 is obtained, which is predominantly from hinge rotations at the base of the building (Figure 10d-f). It can be said that from the hinge status point of view, the procedure produces economical design and a desirable collapse mechanism (i.e., a beam-sway mechanism.)

\subsection{Case-II Building}

The code specified drift for the governing performance level (i.e., 2 percent) and design drifts are not exceeded for any of NTHA drifts (Figure 11). The result shows the method is conservative in attaining the design drifts for the LS performance level. This is because secant stiffness of the frames obtained based on the 2-percent drift is higher than that from 4-percent drift. As a result, elastic higher-mode periods are obtained that produce significant elastic force effects since periods are on the rising and constant plateau of the design acceleration response spectrum. Thus, design for these force effects gives the frames higher strength than required. NTHA drifts decrease as the story increases although this is not the case for the design drift profile (Figure 11). Less discrepancy is obtained between NTHA and design displacements as well as NTHA and design drifts at the lower stories (Figures 11 and 12). NTHA displacements and drifts of the frames show less identical response compared to the Case-I building. The difference of the mean story displacements between the frames at the extreme ends of the buildings (for example, at the 5th story for frame A and E) is 6 percent, at the 13th story for frame A and D 10 percent, and at the 20th story for frame A and C 11 percent (Figure 13a). 


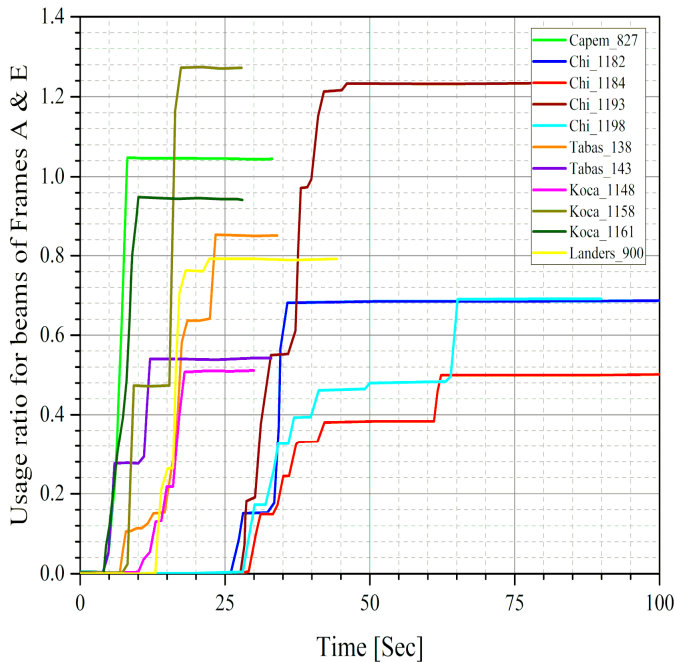

(a)

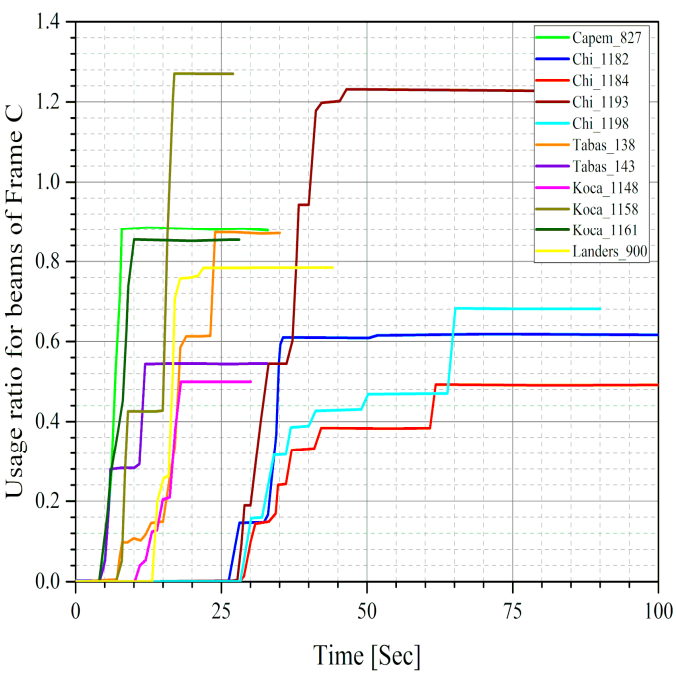

(c)

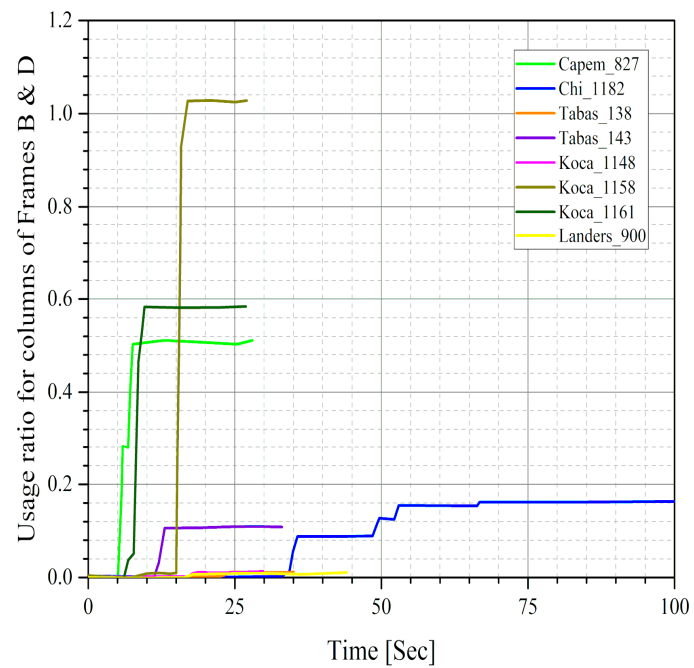

(e)

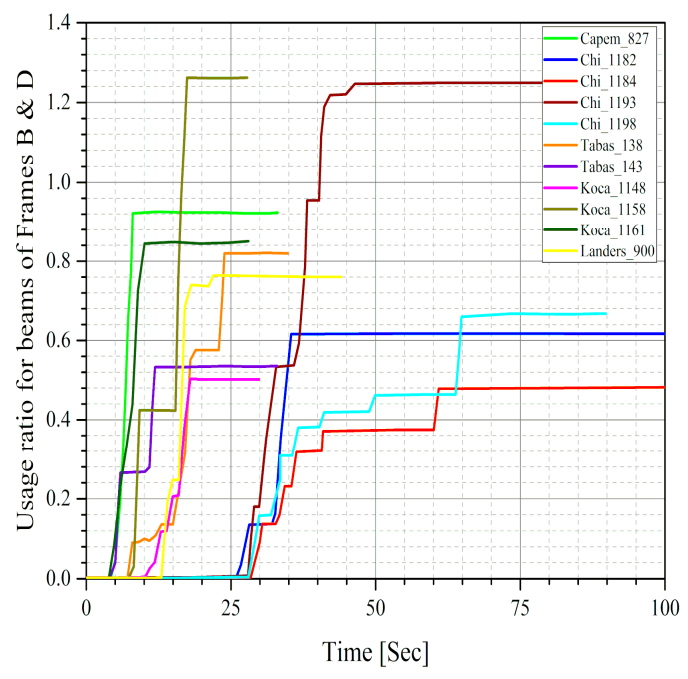

(b)

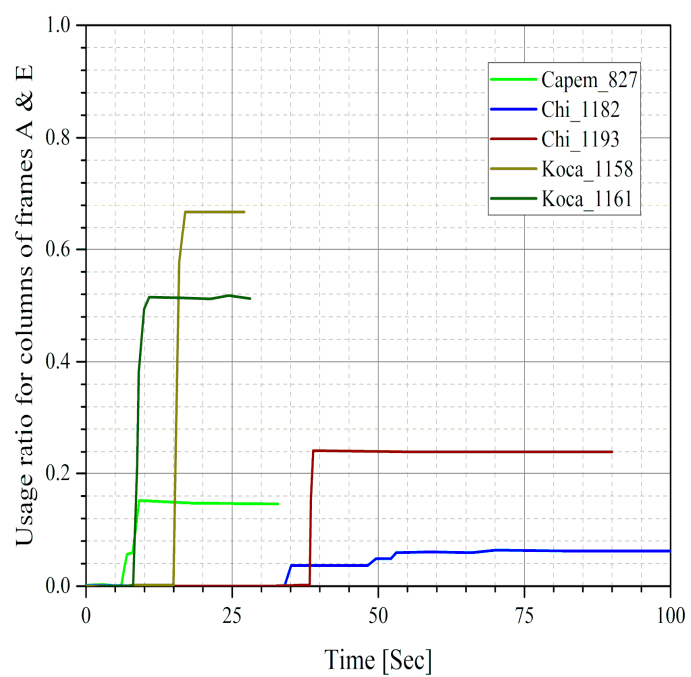

(d)

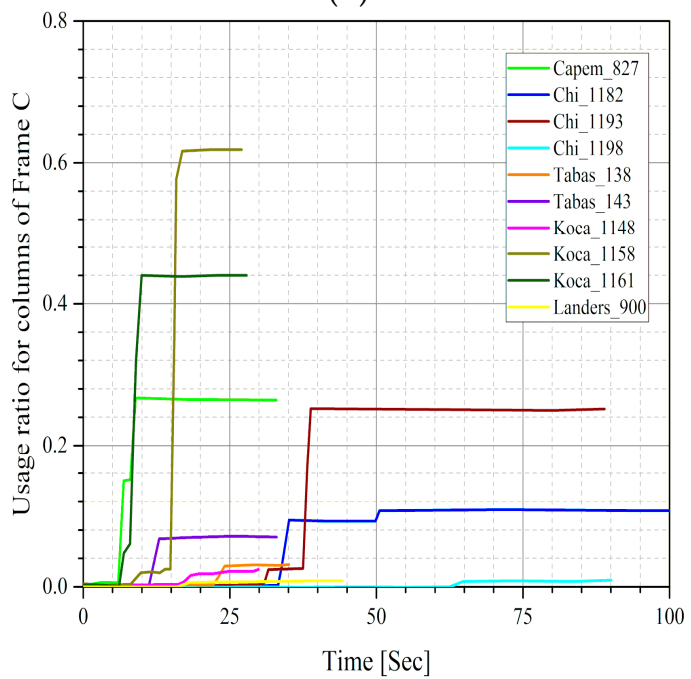

(f)

Figure 10. Usage ratio for the members of Case-I. (a) Case-I frame A\&E-beams' usage ratio; (b) Case-I frame B and D-beams' usage ratio; (c) Case-I frame C-beams' usage ratio; (d) Case-I frame A and E-columns' usage ratio; (e) Case-I frame B and D-columns' usage ratio; (f) Case-I frame C-columns' usage ratio. 


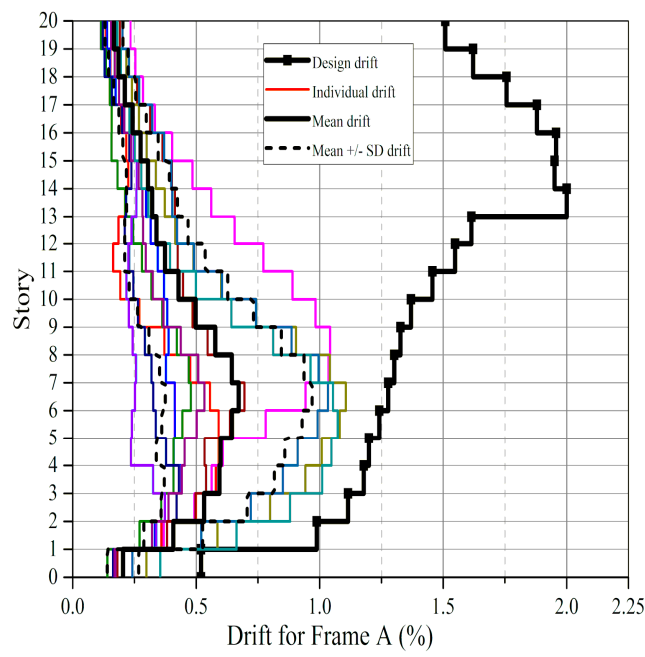

(a)

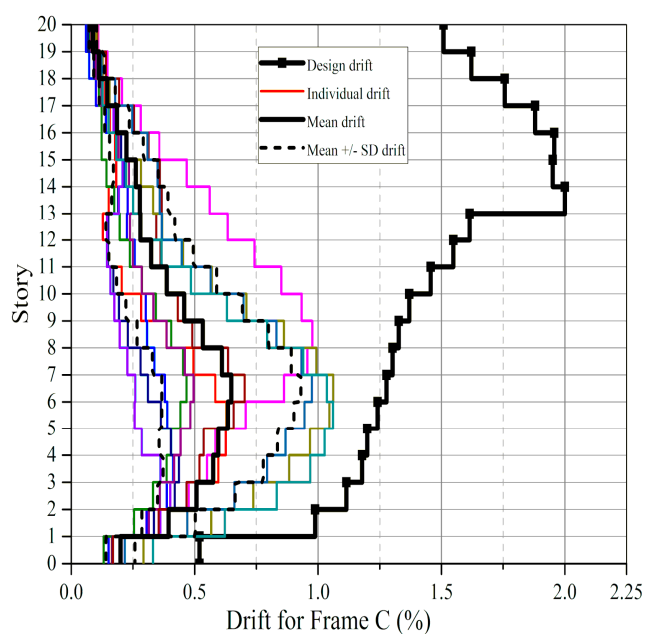

(c)

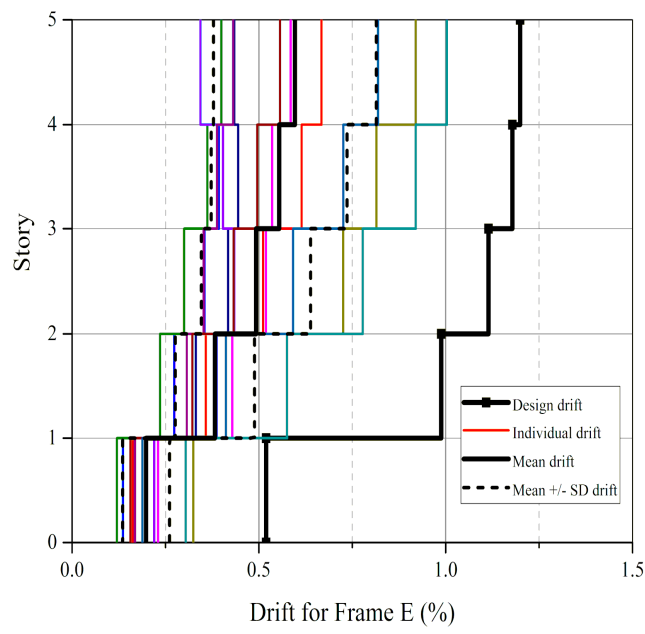

(e)

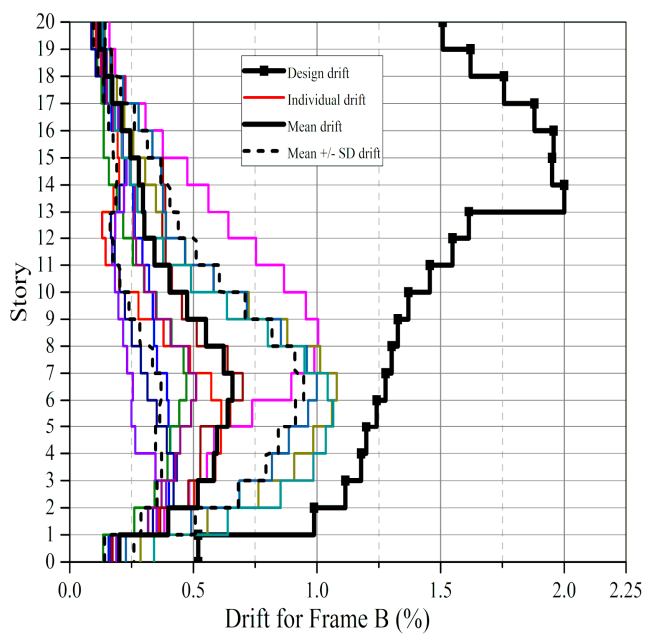

(b)

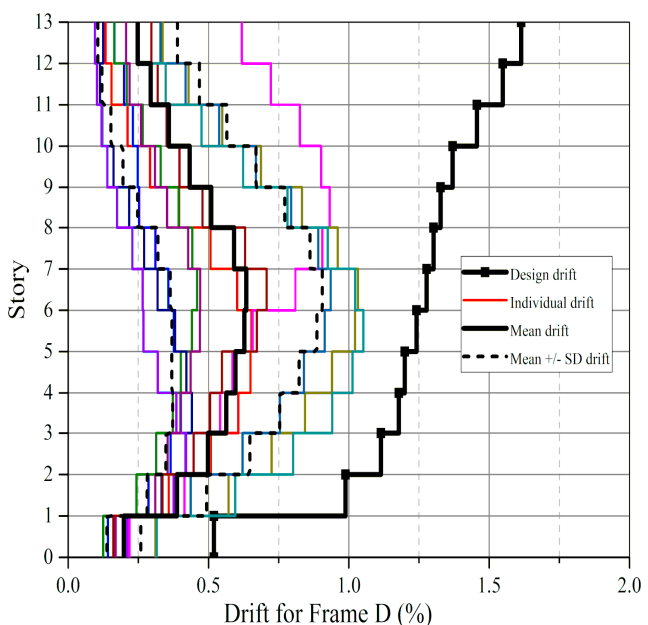

(d)

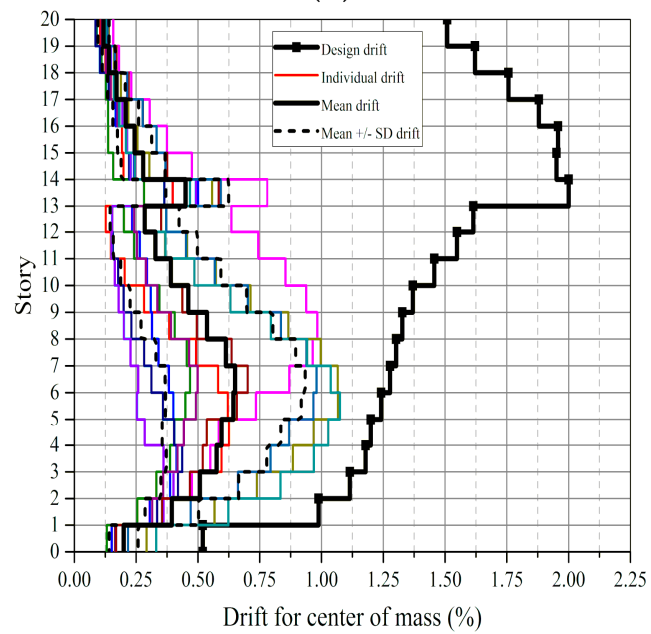

(f)

Figure 11. Case-II drift. (a) Case-II frame A's drift; (b) Case-II frame B's drift; (c) Case-II frame C's drift; (d) Case-II frame D's drift; (e) Case-II frame E's drift; (f) Case-II center of mass's drift. 


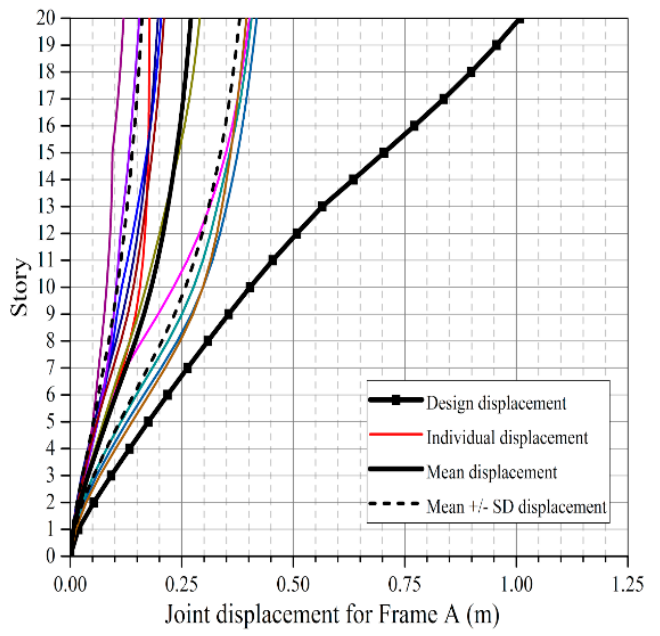

(a)

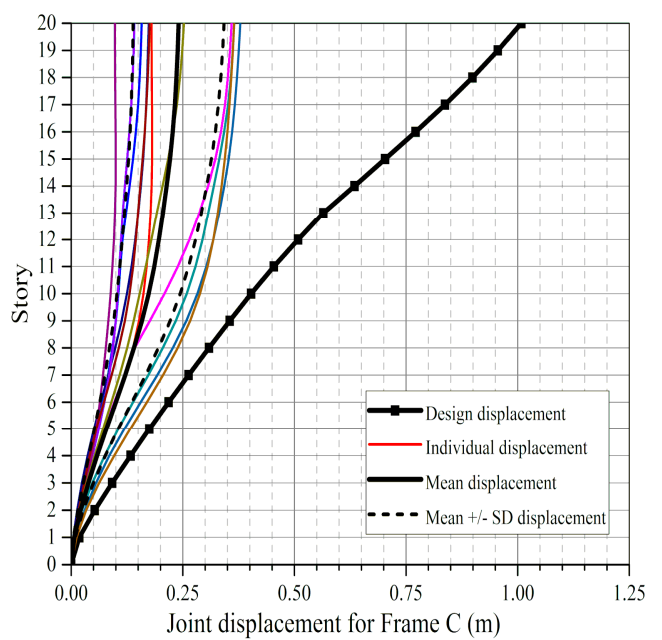

(c)

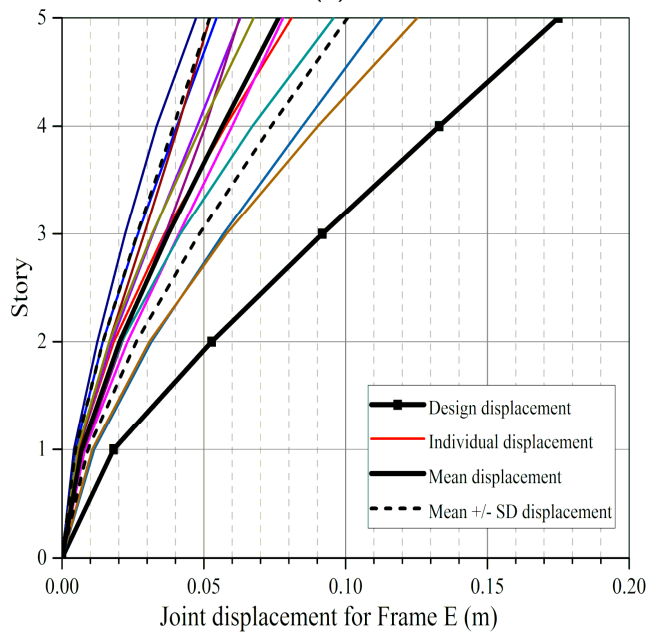

(e)

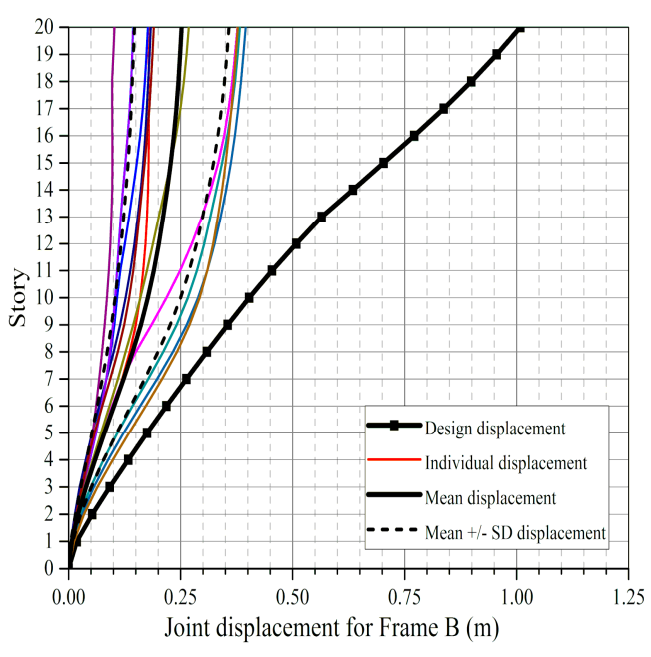

(b)

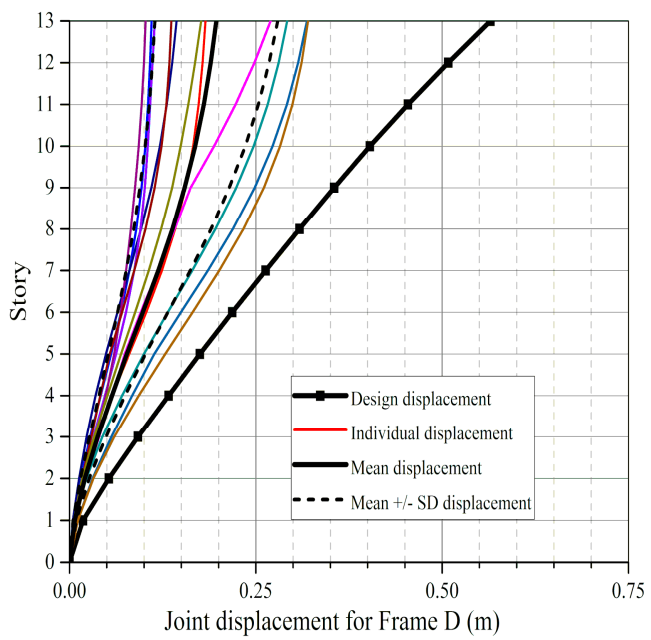

(d)

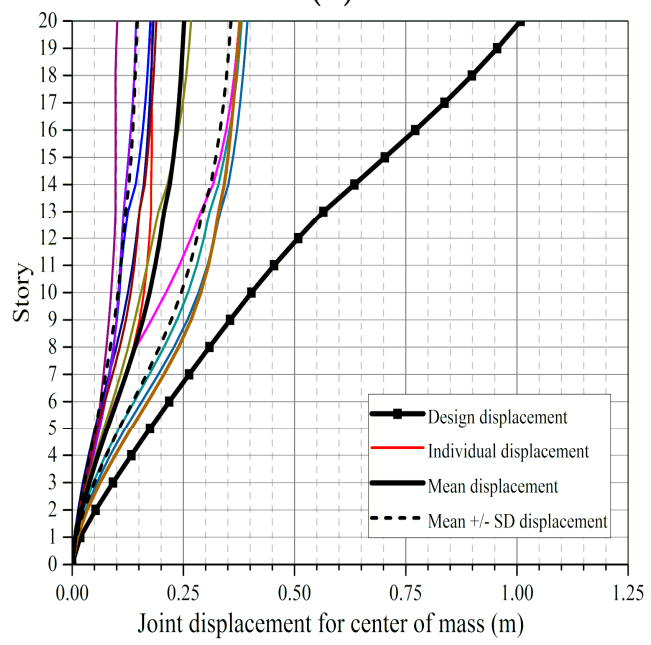

(f)

Figure 12. Case-II story's displacements. (a) Case-II frame A's displacement; (b) Case-II frame B's displacement; (c) Case-II frame C's displacement; (d) Case-II frame D's displacement; (e) Case-II frame E's displacement; (f) Case-II center of mass displacement. 


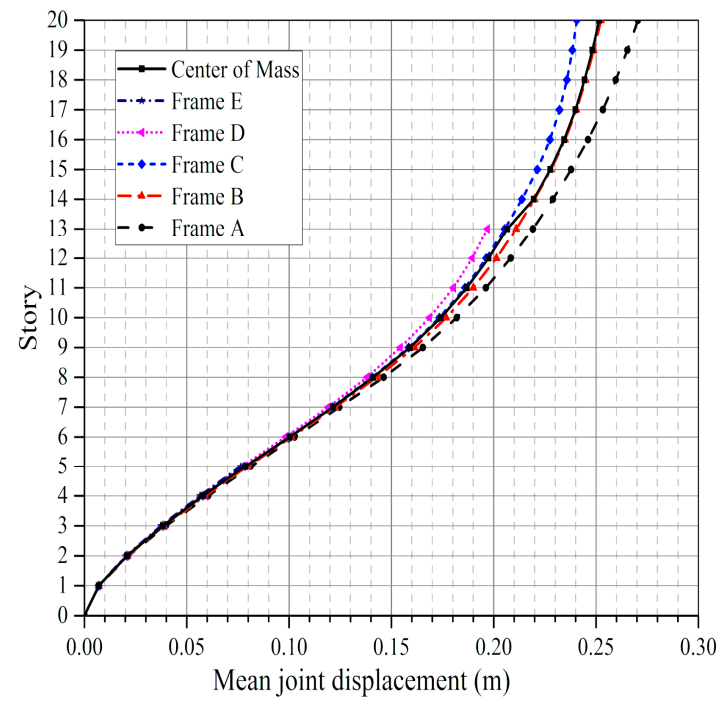

(a)

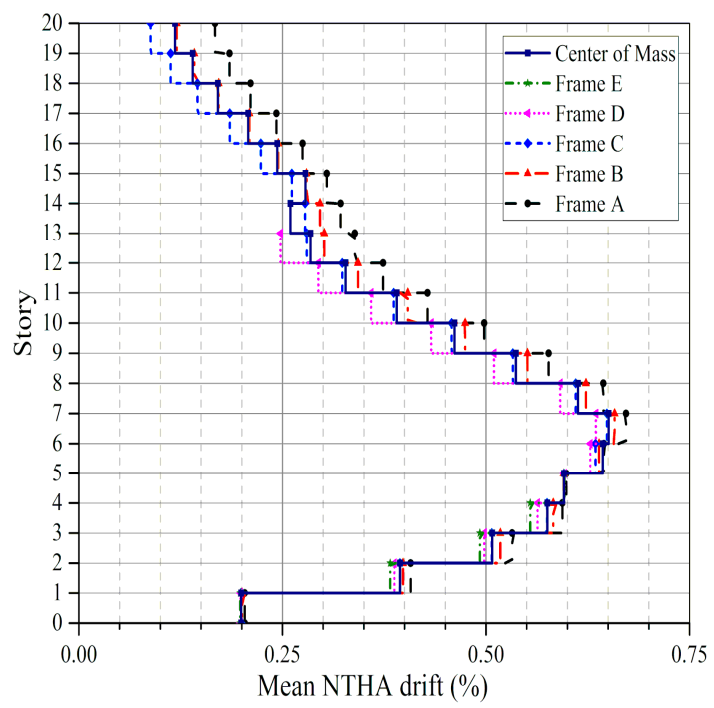

(b)

Figure 13. (a) Mean story displacement for Case-II; (b) Mean drifts for Case-II.

Beam usage ratios for the frames range from 0.4 to 0.45 with an average of 0.43 (Figure 14a-e), while for the columns the usage ratios vary between 0.02 and 0.033 , and the mean is 0.03 (Figure 14f-j). The ranges show that similar seismic demands are imposed on each frame, which indicates that uneven responses of frames due to floor rotations (global torsion) are insignificant. Conservatism for the ranges can be minimized by redesigning members, but since the aim is to check the performance of the procedure without redesigning members, it can be inferred that the safety is ensured using the proposed design procedure.

In general, low mean NTHA outputs are produced compared to the design outputs. Factors affecting the outputs include the following:

- To reduce computational effort and time, the design should not be done for each member. Members having similar analysis outputs must be grouped in one category, and design has to be performed for the maximum output from the category. Consequently, some members' design will be conservative.

- Negative and positive moment capacities of beams, though different values, are the same on a given bay. Thus, some beams will have higher strength than needed.

- The choice of amplification factor $\left(\varphi^{0} / \varphi_{s}\right)$ applied to columns forces affect the design.

- The empirical equations of yield drift and equivalent viscous damping ratio induce errors. 


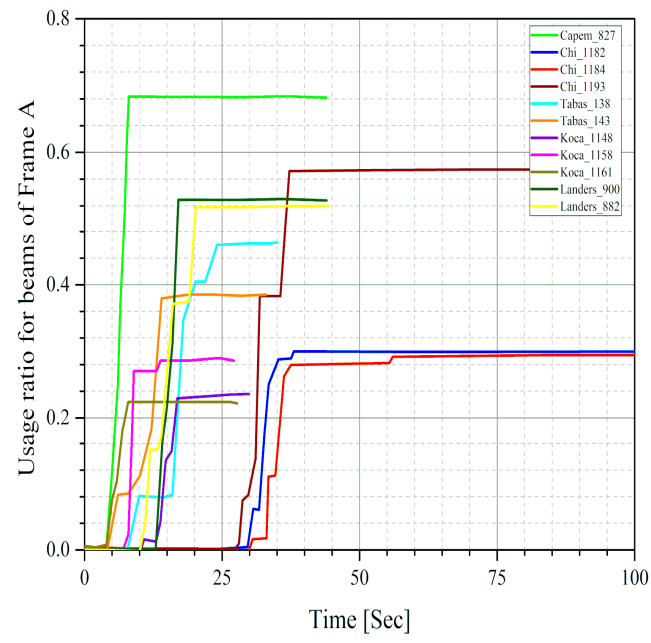

(a)

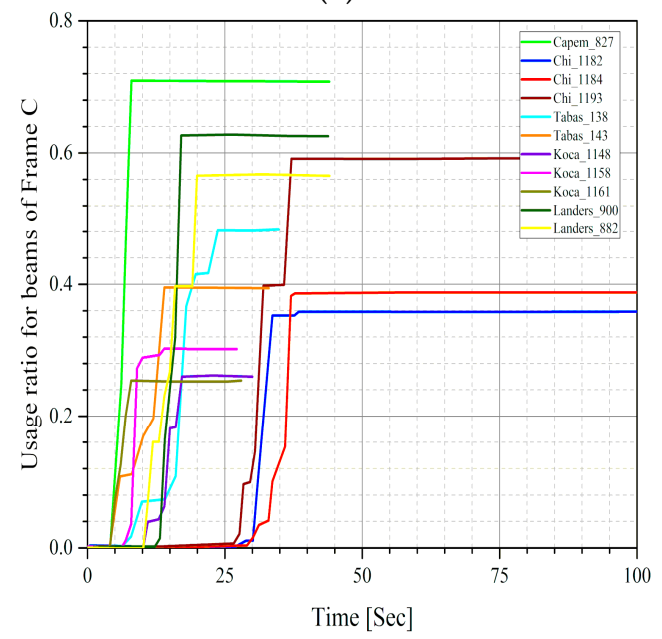

(c)

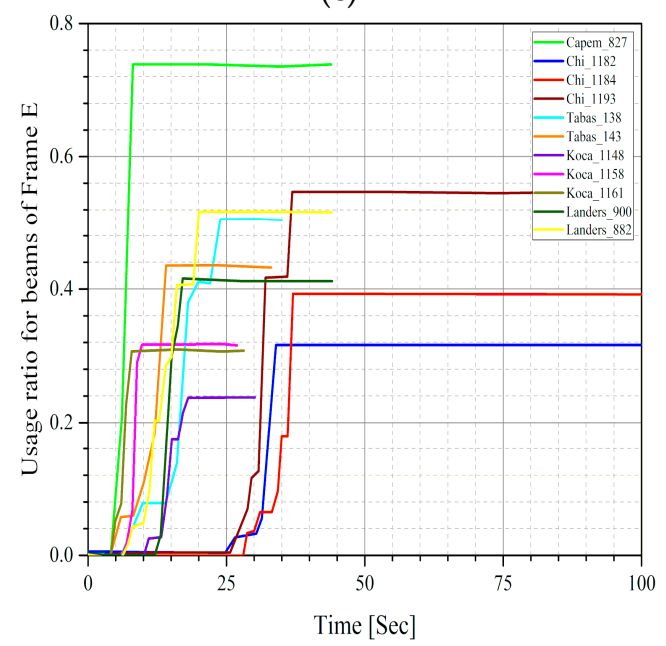

(e)

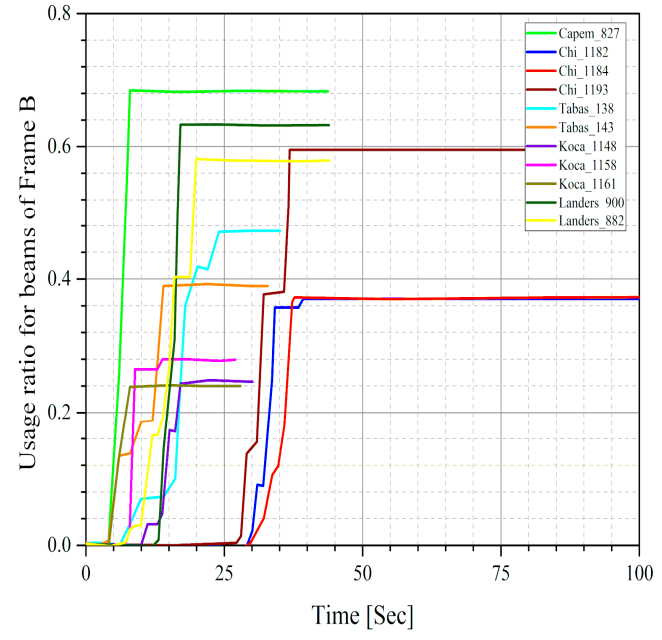

(b)

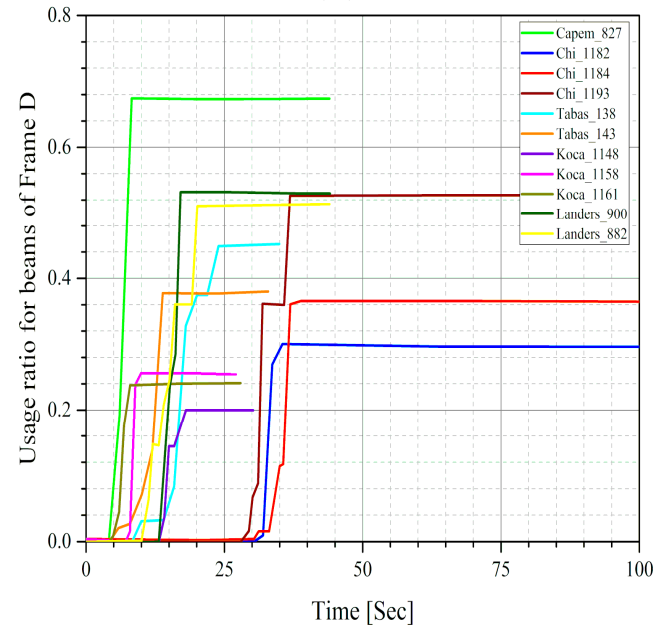

(d)

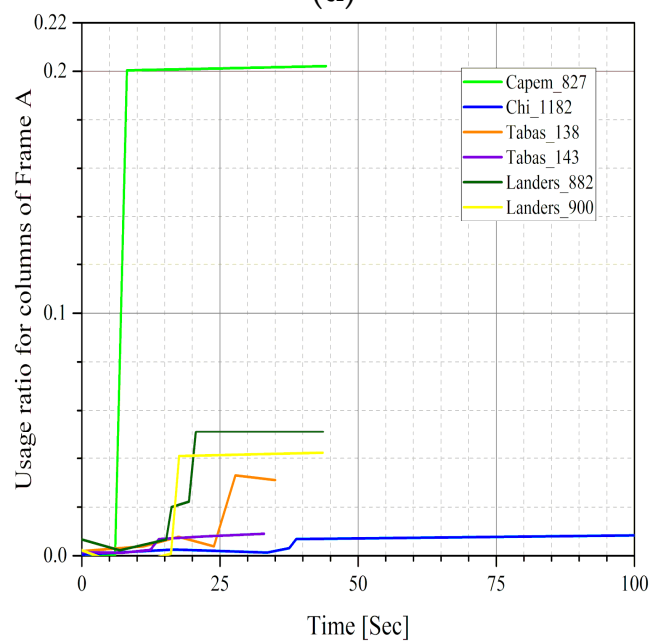

(f)

Figure 14. Cont. 


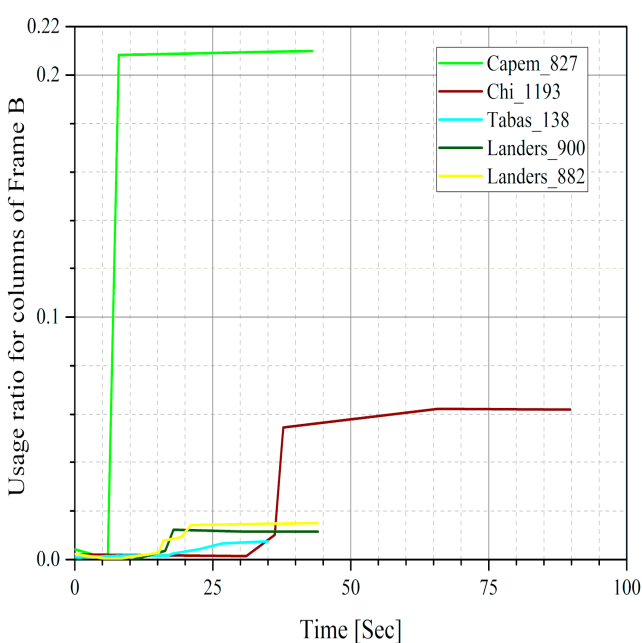

(g)

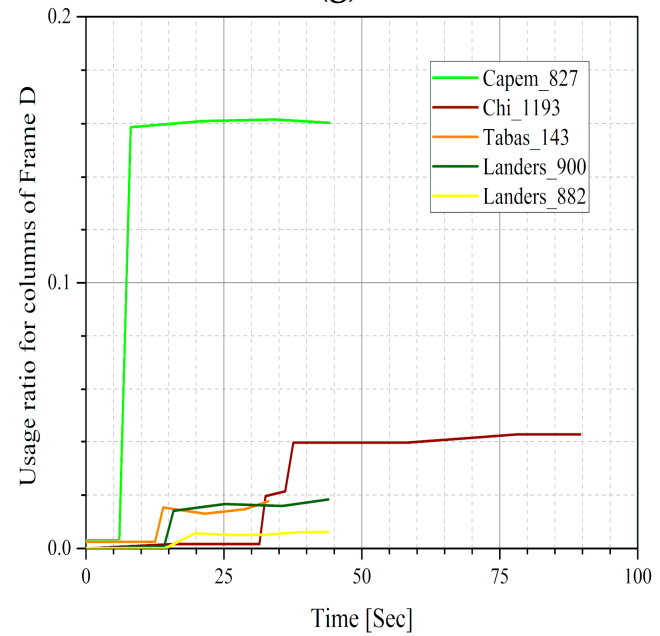

(i)

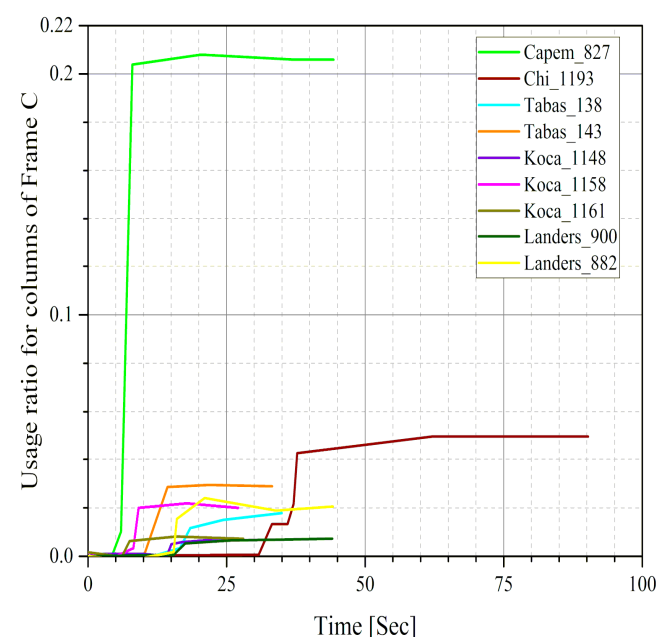

(h)

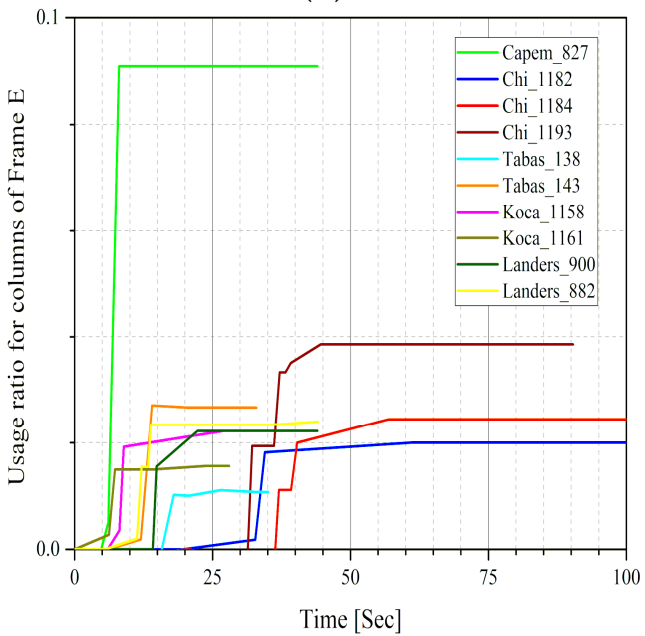

(j)

Figure 14. Usage ratio for the members of Case-II. (a) Case-II frame A-beams'usage ratio; (b) Case-II frame B-beams' usage ratio; (c) Case-II frame C-beams' usage ratio; (d) Case-II frame D-beams' usage ratio; (e) Case-II frame E-beams'usage ratio; (f) Case-II frame A-columns' usage ratio; (g) Case-II frame B-columns' usage ratio; (h) Case-II frame C-columns' usage ratio; (i) Case-II frame D-columns' usage ratio; (j) Case-II frame E-columns' usage ratio.

\section{Conclusions}

A performance-based seismic design procedure is proposed to account for torsional and higher-mode responses in the DDBD of plan-asymmetric RC frame buildings. In the procedure, a technique is developed to minimize torsional response by assigning secant stiffness of the frames that eliminate the eccentricity between the centers of secant-stiffness rigidity and supported mass (the mass on and above that story). To define the design story displacements, the procedure employs a modal analysis and scales the mode shapes so that allowable story drift is not exceeded. In such a way, the effect of stiffness and mass irregularity along the height are considered. The P- $\Delta$ effect is included using a non-parametric equation, which is applicable for general cases.

The procedure does not exceed the allowable story drifts of the intended performance levels though the mean NTHA displacements and drifts are low compared to the design displacements and drifts. It greatly reduces the floor rotations of the building with mass and stiffness irregularity along the height. Translational and rotational coupling has become insignificant, and approximately only translational motion is achieved when subjected to the ground motions. Allowable hinge rotations are compared with the corresponding mean NTHA outputs by usage ratios. It was observed that the 
mean NTHA outputs of usage ratios are within a tolerable limit, and uniform responses for each frame are obtained. The target failure mechanism (i.e., the beam-sway mechanism) is also achieved.

At the current stage, the proposed design method has been tested for moment-resisting RC frame buildings subjected to uni-directional ground motions. The proposed procedure is found to produce designs that achieve the performance objective without redesigning members. It is hoped that upon using the procedure, a step forward is undertaken toward rendering NTHA less necessary, thereby saving computational resources and effort.

Future research should consider the effect of bi-directional ground motions on the proposed method. The applicability of the method to buildings made of steel, precast, prestressed, composite, FRP reinforced, etc., should be checked. It should also be investigated for sufficient samples of lateral-load resisting systems other than rigid-frame buildings such as braced, wall, and wall-frame buildings.

Author Contributions: B.H.A. proposed the seismic design procedure, produced the numerical models and verified using NTHA. All the tasks are undertaken under the guidance and supervision of J.S.L.

Funding: This research was supported by Grant No. NRF-2017M2B2B1072890 from the National Research Foundation of Korea (NRF) funded by the Korean government (MSIP: Ministry of Science, Information and Communication Technology (ICT), and Future Planning) and Grant No. 17IFIP-B067108-05 from the Korea Agency for Infrastructure Technology Advancement funded by Ministry of Land, Infrastructure and Transport.

Acknowledgments: We thank the reviewers for their valuable comments, which improved the contents of the article. We are grateful to Amy Ostrander for assisting in editing and formatting.

Conflicts of Interest: The authors declare no conflict of interest.

\section{Notations}

Latin letters

$\boldsymbol{b}_{\text {ref }} \quad$ Number of beams for the reference frame

$\boldsymbol{b}_{j} \quad$ Number of beams for the $j$-th frame

$c_{\text {ref }} \quad$ Number of columns for the reference frame

$c_{j} \quad$ Number of columns for the $j$-th frame

$d_{b l} \quad$ Diameter of rebar

$D_{1} \quad$ Spectral displacement for the first mode

$e_{x, k} \quad$ In-plane eccentricity between centers of rigidity and supported mass at story $k$

$E_{c, r e f} \quad$ Young Modulus for concrete of the reference frame

$E_{c, j} \quad$ Young Modulus for concrete of the $j$-th frame

$f^{\prime}{ }_{c} \quad$ Concrete cylinder compressive strength (specified compressive concrete strength)

$f_{u} \quad$ Ultimate strength of the rebar

$f_{y} \quad$ Yield strength of the rebar

$f_{y e} \quad$ Expected yield strength of the rebar

$\boldsymbol{F}_{i} \quad$ Lateral force at story $i$ obtained using DDBD's procedure

$\boldsymbol{H}_{\boldsymbol{n}} \quad n$-th story height or roof height

$H_{i} \quad i$-th story height

$\boldsymbol{H}_{\text {eff }} \quad$ Effective height

$d_{b} \quad$ Depth of a beam

$I_{g b} \quad$ Gross moment of inertia for a beam

$I_{g c} \quad$ Gross moment of inertia for a column

$K_{k} \quad$ Lateral stiffness of a frame at story $k$

$K_{\text {inital }} \quad$ Secant stiffness matrix of the frames with $I_{g b}$ and $I_{g c}$ modified by $\alpha_{b}, \alpha_{c}, \gamma, \eta_{b}$ and $\eta_{c}$

$K_{\text {final }} \quad$ Secant stiffness matrix of the frames with $I_{g b}$ and $I_{g c}$ modified by $\alpha^{\prime}{ }_{b}, \alpha^{\prime}{ }_{c}, \gamma, \eta_{b}$ and $\eta_{c}$

$K_{r e f, k} \quad k$-th story's secant stiffness for the reference frame 


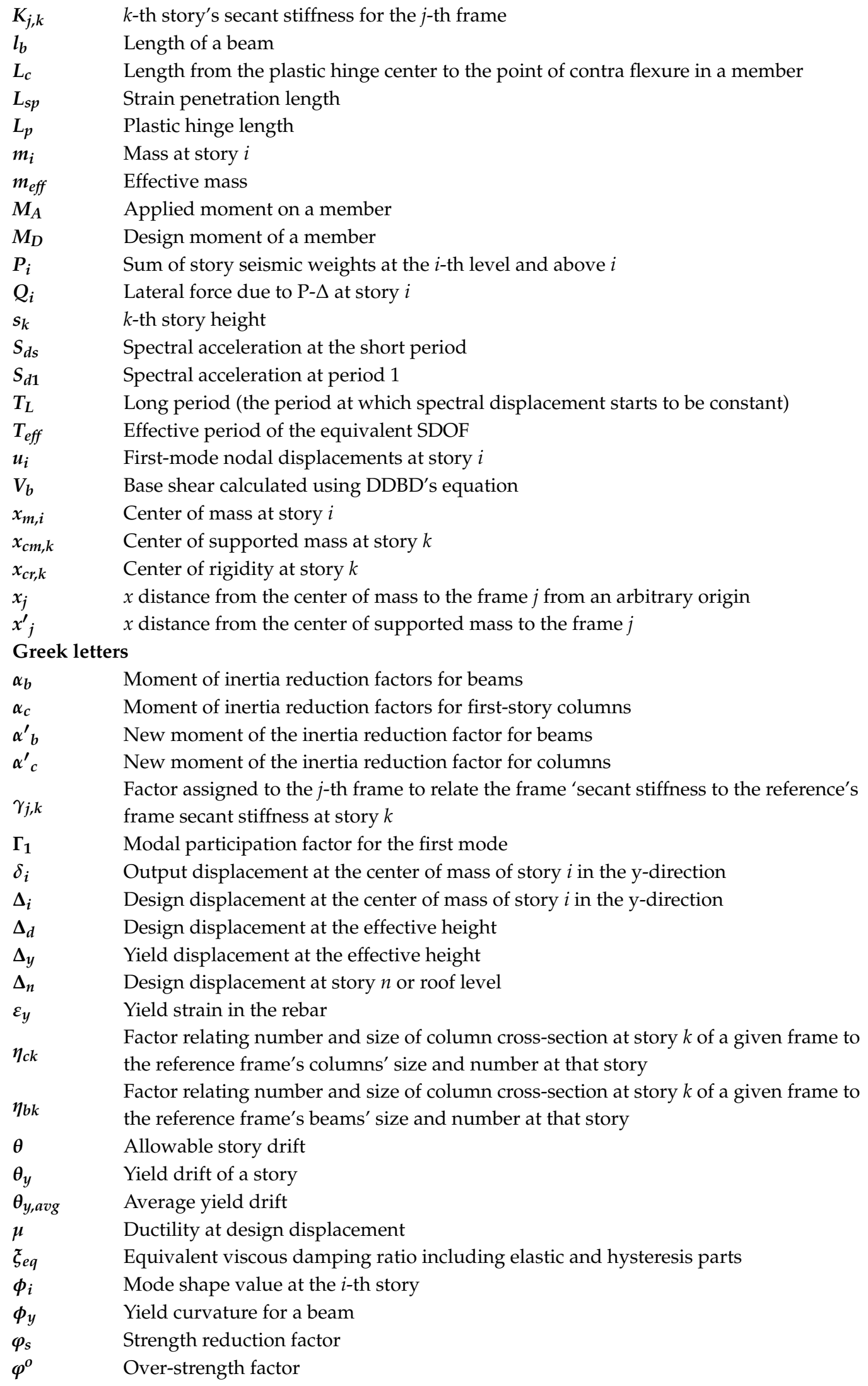

\section{Appendix A}

According to DDBD's principle, a multi-story frame subjected to lateral forces is represented by the equivalent Single Degree Of Freedom (SDOF) system as shown in Figure A1 below. 


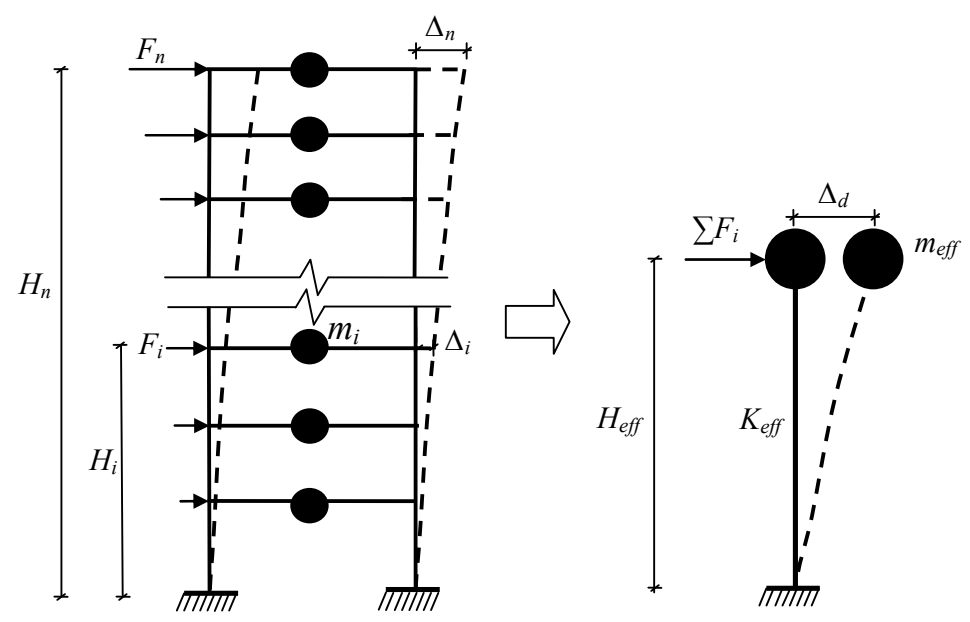

Figure A1. Representation of the multi-story frame by a SDOF system.

Let design displacement, height to story $i$ and mass at story $i$ be given as $\Delta_{i}, h_{i}$ and $m_{i}$, respectively, and the effective height, $H_{\text {eff, }}$, be given as

$$
H_{e f f}=\frac{\sum_{i=1}^{n} m_{i} \Delta_{i} H_{i}}{\sum_{i=1}^{n} m_{i} \Delta_{i}}
$$

Design displacement for the SDOF system, $\Delta_{d}$, is

$$
\Delta_{d}=\frac{\sum_{i=1}^{n} m_{i} \Delta_{i}^{2}}{\sum_{i=1}^{n} m_{i} \Delta_{i}}
$$

Effective mass, $m_{\text {eff, }}$ is given as

$$
m_{e f f}=\frac{\sum_{i=1}^{n} m_{i} \Delta_{i}}{\Delta_{d}}
$$

For RC frames, yield drift ratio $\theta_{y}$ is

$$
\theta_{y}=\frac{0.5 \varepsilon_{y} l_{b}}{d_{b}}
$$

where $l_{b}, d_{b}$ and $\varepsilon_{y}$ are beam span length, beam depth and yield strain, respectively.

For more than one bay on a given story, average yield drift ratio $\theta_{y, a v g}$ is obtained using Equation (A5) based on the rationale that equal moment capacities are assigned to each beam but not necessarily equal negative and positive moments as discussed by Priestley et al. [37].

$$
\theta_{y, a v g}=\frac{\sum_{i=1}^{n} \theta_{y i}}{n}
$$

where $n$ is the number of bays.

Yield displacement, $\Delta_{y}$, at the effective height is found as

$$
\Delta_{y}=\theta_{y, a v g} H_{e f f}
$$

Ductility, $\mu$, at the design displacement is

$$
\mu=\frac{\Delta_{d}}{\Delta_{y}}
$$

For RC frames, Equation (A8) is used to calculate the equivalent viscous damping ratio, $\xi_{\text {eq }}$

$$
\xi_{\text {eq }}=0.05+0.565\left(\frac{\mu-1}{\mu \pi}\right)
$$


Using the displacement response spectrum for $\xi_{e q}$ and $\Delta_{d}$, the effective period, $T_{\text {eff, }}$, can be obtained. The effective stiffness, $K_{\text {eff, }}$ and the base shear, $V_{b}$, can then be determined as shown in Equations (A9) and (A10), respectively.

$$
\begin{aligned}
K_{e f f} & =\frac{4 \pi^{2} m_{e f f}}{T_{e f f}^{2}} \\
V_{b} & =K_{e f f} \Delta_{d}
\end{aligned}
$$

The base shear is distributed up the height of the building as a set of equivalent lateral forces, $F_{i}$, using Equation (A11).

$$
F_{i}=V_{b} \frac{m_{i} \Delta_{i}}{\sum_{i=1}^{n} m_{i} \Delta_{i}}
$$

\section{References}

1. Bertero, R.D.; Bertero, V.V. Performance-based seismic engineering: The need for a reliable conceptual comprehensive approach. Earthq. Eng. Struct. Dyn. 2002, 31, 627-652. [CrossRef]

2. Collins, K.R.; Stojadinovic, B. Limit states for performance-based design. In Proceedings of the 12th World Conference on Earthquake Engineering, Auckland, New Zealand, 30 January-4 February 2000.

3. Castaldo, P.; Palazzo, B.; Alfano, G.; Palumbo, M.F. Seismic reliability-based ductility demand for hardening and softening structures isolated by friction pendulum bearings. Struct. Control Health Monit. 2018, 25, e2256. [CrossRef]

4. Priestley, M.J.N. Myths and fallacies in earthquake engineering-Conflicts between design and reality. Bull. N. Z. Natl. Soc. Earthq. Eng. 1993, 26, 329-341.

5. Mohele, J.P. Displacement-based design of RC structures subjected to earthquakes. Earthq. Spectra 1992, 8 , 403-428. [CrossRef]

6. Applied Technology Council (ATC) 40. Seismic Evaluation and Retrofit of Concrete Buildings; ATC: Redwood City, CA, USA, 1997.

7. Aschheim, M.; Black, E.F. Yield point spectra for seismic design and rehabilitation. Earthq. Spectra 2000, 16, 317-336. [CrossRef]

8. Chopra, A.K.; Goel, R.K. Direct displacement-based design: Use of inelastic vs. elastic design spectra. Earthq. Spectra 2001, 17, 47-64. [CrossRef]

9. Castillo, R. Seismic Design of Asymmetric Ductile Systems. Ph.D. Thesis, University of Canterbury, Christchurch, New Zealand, 2004.

10. Hejal, R.; Chopra, A.K. Earthquake response of torsionally coupled frame buildings. J. Struct. Eng. 1989, 115, 834-851. [CrossRef]

11. Fazileh, F. Displacement-Based Seismic Design of RC Wall-Frame Buildings and Asymmetric Plan Buildings. Ph.D. Thesis, Carleton University, Ottawa, ON, Canada, 2011.

12. Colajanni, P.; Cacciola, P.; Potenzone, B.; Spinella, N.; Testa, G. Non linear and linearized combination coefficients for modal pushover analysis. Ing. Sismica 2017, 34, 93-112.

13. Ferraioli, M. Multi-mode pushover procedure for deformation demand estimates of steel moment-resisting frames. Int. J. Steel Struct. 2017, 17, 653-676. [CrossRef]

14. Ferraioli, M.; Lavino, A.; Mandara, A. An adaptive capacity spectrum method for estimating seismic response of steel moment-resisting frames. Int. J. Earthq. Eng. 2016, 1-2, 47-60.

15. Kaatsız, K.; Sucuoğlu, H. Generalized force vectors for multi-mode pushover analysis of torsionally coupled systems. Earthq. Eng. Struct. Dyn. 2014, 43, 2015-2033. [CrossRef]

16. Kreslin, M.; Fajfar, P. The extended N2 method considering higher mode effects in both plan and elevation. Bull. Earthq. Eng. 2012, 10, 695-715. [CrossRef]

17. Landi, L.; Pollio, B.; Diotallevi, P.P. Effectiveness of different standard and advanced pushover procedures for regular and irregular RC frames. Struct. Eng. Mech. 2014, 51, 433-446. [CrossRef]

18. De Stefano, M.; Pintucchi, B. A review of research on seismic behaviour of irregular building structures since 2002. Bull. Earthq. Eng. 2008, 6, 285-308. [CrossRef] 
19. Chopra, A.K.; Goel, R.K. A modal pushover analysis procedure for estimating seismic demands for buildings. Earthq. Eng. Struct. Dyn. 2002, 31, 561-582. [CrossRef]

20. Wilkinson, P.J.; Lavan, O. A modal displacement based approach for th seismic design of one way asymmetric multi story buildings. In Proceedings of the Advances in Structural Engineering and Mechanics, Jeju Island, Korea, 8-12 September 2013.

21. Wilkinson, P.J.; Lavan, O. Practical modal pushover design of one-way asymmetric-plan reinforced concrete wall buildings for unidirectional ground motion. Bull. Earthq. Eng. 2015, 13, 2915-2944. [CrossRef]

22. Reyes, J.C.; Chopra, A.K. Evaluation of three-dimensional modal pushover analysis for unsymmetric-plan buildings subjected to two components of ground motion. Earthq. Eng. Struct. Dyn. 2011, 40, 475-1494. [CrossRef]

23. Georgoussis, G.K. Preliminary structural design of wall-frame systems for optimum torsional response. Int. J. Concr. Struct. 2017, 11, 45-58. [CrossRef]

24. Bahmani, P.; van de Lindt, J.W.; Dao, T.N. Displacement-based design of buildings with torsion: Theory and verification. J. Struct. Eng. 2013, 140. [CrossRef]

25. Kan, C.L.; Chopra, A.K. Elastic earthquake analysis of torsionally coupled multi-story buildings. Earthq. Eng. Struct. Dyn. 1977, 5, 395-412. [CrossRef]

26. Beyer, K. Seismic Design of Torsionally Eccentric Buildings with U-Shaped RC Walls. Ph.D. Thesis, University of Pavia, Pavia, Italy, 2008.

27. Paparo, A.; Landi, L.; Diotallevi, P.P. Extension of direct displacement-based design to plan-asymmetric RC frame buildings. J. Civ. Eng. Archit. 2012, 6, 1280.

28. Loeding, S.; Kowalsky, M.J.; Priestley, M.J.N. Displacement-Based Design Methodology Applied to RC Building Frames; Technical Report SSRP-98(06); University of California San Diego: San Diego, CA, USA, 1998.

29. Pettinga, J.D.; Priestley, M.N. Dynamic behavior of reinforced concrete frames designed with direct displacement-based design. J. Earthq. Eng. 2005, 9, 309-330. [CrossRef]

30. Suarez, V. Evaluation of Displacement-Based Seismic Design of Reinforced Concrete Building Frames. Ph.D. Thesis, North Carolina State University, Raleigh, NC, USA, 2014.

31. Amaris, A.D.; Priestley, M.J.N. Dynamic Amplification of Seismic Moments and Shear Forces in Cantilever Walls; ROSE Research Report 2002/01; University of Pavia: Pavia, Italy, 2002.

32. Priestley, M.J.N. Myths and Fallacies in Earthquake Engineering; revisited; The Ninth Mallet Milne Lecture; IUSS Press: Pavia, Italy, 2003.

33. Sullivan, T.J.; Priestley, M.J.; Calvi, G.M. Direct displacement-based design of frame-wall structures. J. Earthq. Eng. 2006, 10, 91-124. [CrossRef]

34. Cheng, F. Matrix Analysis of Structural Dynamics, 1st ed.; Marcel Dekker: New York, NY, USA, 2000; ISBN 0-8427-0387-1.

35. Abebe, B.H.; Lee, J.S. Extension of direct displacement-based design to include higher-mode effects in planar reinforced concrete frame buildings. J. Earthq. Eng. Soc. Korea 2018, 22, 299-309. [CrossRef]

36. Smith, B.S.; Coull, A. Tall Building Structures: Analysis and Design, 1st ed.; John Wiley \& Sons: New York, NY, USA, 1991; ISBN 0-471-51237-0.

37. Priestley, M.J.N.; Calvi, G.M.; Kowalsky, M.J. Displacement-Based Seismic Design of Structures, 1st ed.; IUSS Press: Pavia, Italy, 2007; ISBN 978-88-6198-000-6.

38. SeismoSpect. Seismosoft, Earthquake Engineering Software Solutions; SeismoSpect: Pavia, Italy, 2016.

39. MacGregor, J.G.; Wight, J.K.; Teng, S.; Irawan, P. Reinforced Concrete: Mechanics and Design, 6th ed.; Prentice Hall: Englewood Cliffs, NJ, USA, 1997; ISBN 978-0-13-217652-1.

40. Ali, M.M.; Moon, K.S. Structural developments in tall buildings: Current trends and future prospects. Archit. Sci. Rev. 2007, 50, 205-223. [CrossRef]

41. Federal Emergency Management Agency (FEMA). Prestandard and Commentary for the Seismic Rehabilitation of Buildings; FEMA: Washington, DC, USA, 2000.

42. PEER Strong Motion Database. Available online: http:/ / www.peer.berkeley.edu (accessed on 7 May 2018).

43. Kowalsky, M.J. A displacement-based approach for the seismic design of continuous concrete bridges. Earthq. Eng. Struct. Dyn. 2002, 31, 719-747. [CrossRef] 
44. Kappos, A.J.; Gidaris, I.G.; Gkatzogias, K.I. Problems associated with direct displacement-based design of concrete bridges with single-column piers, and some suggested improvements. Bull. Earthq. Eng. 2012, 10, 1237-1266. [CrossRef]

45. Ghodsi, T.; Ruiz, J.A.F. Pacific earthquake engineering research/seismic safety commission tall building design case study 2. Struct. Des. Tall Spec. Build. 2010, 19, 197-256. [CrossRef] 